Document downloaded from:

http://hdl.handle.net/10251/68532

This paper must be cited as:

Li, Z.; Martínez Triguero, LJ.; Concepción Heydorn, P.; Yu, J.; Corma Canós, A. (2013). Methanol to olefins: activity and stability of nanosized SAPO-34 molecular sieves and control of selectivity by silicon distribution. Physical Chemistry Chemical Physics. 15(35):1467014680. doi:10.1039/c3cp52247d.

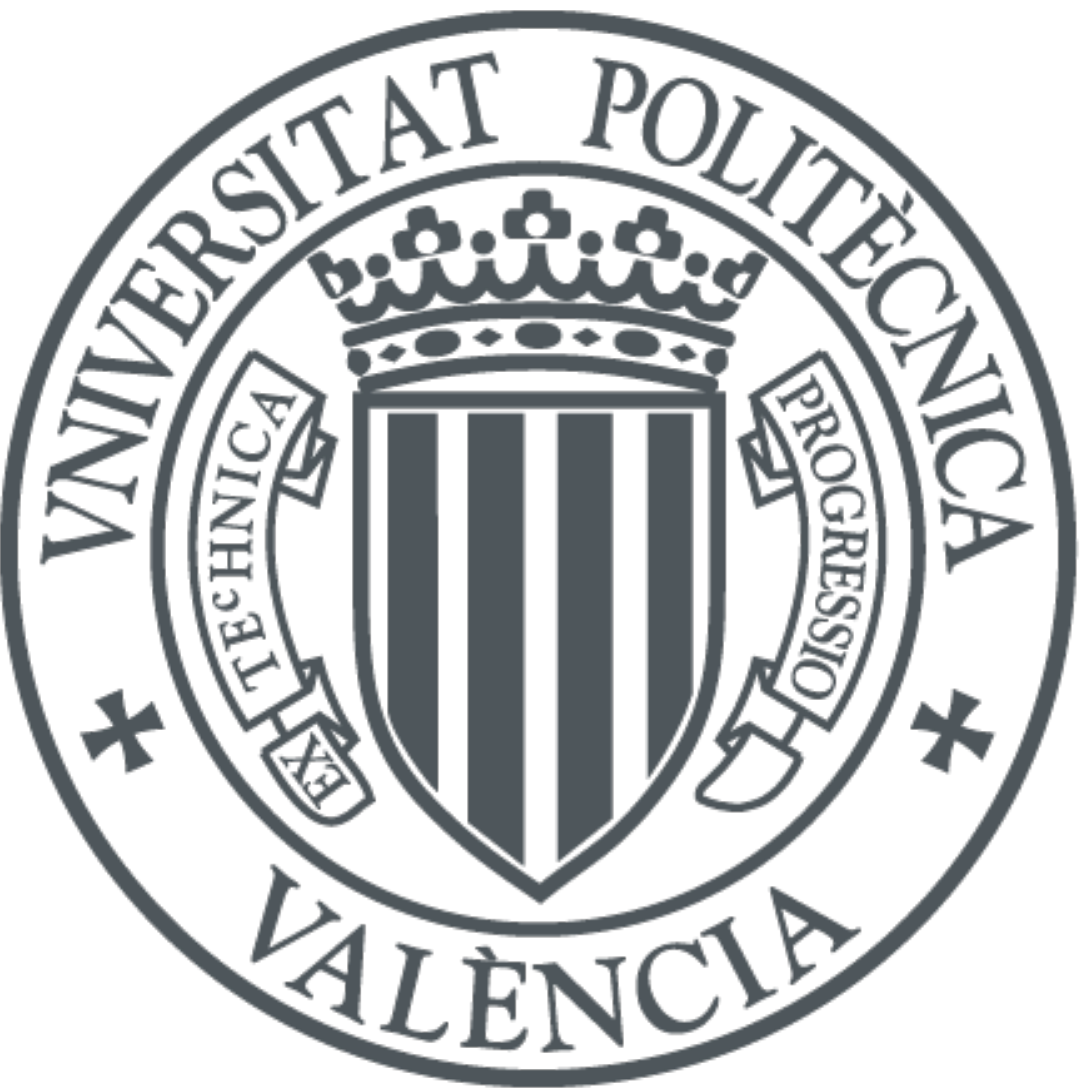

The final publication is available at

https://dx.doi.org/10.1039/c3cp52247d

Copyright Royal Society of Chemistry

Additional Information 


\section{Methanol to olefins: Activity, stability of nanosized SAPO-34 molecular sieve and control of selectivity by silicon distribution}

Zhibin Li ${ }^{1}$, Joaquin Martínez-Triguero ${ }^{1}$, Patricia Concepción ${ }^{1}$, Jihong $\mathrm{Yu}^{2}$, Avelino Corma ${ }^{1 *}$

${ }^{1}$ Instituto de Tecnología Química (UPV-CSIC), Universidad Politécnica de Valencia, Consejo Superior de Investigaciones Científicas, Av. de los Naranjos s/n, 46022 Valencia, Spain

${ }^{2}$ State Key Laboratory of Inorganic Synthesis and Preparative Chemistry, College of Chemistry, Jilin University, Changchun, 130021.China.

* Corresponding author:

Prof. Avelino Corma

E-mail address: acorma@itq.upv.es

Instituto de Tecnología Química, UPV-CSIC, Campus de la Universitat Politècnica de València Avda. Los Naranjos s/n; 46022 Valencia (Spain)

(+34) 963877800 


\begin{abstract}
NanoSAPO-34 molecular sieve synthesized in microwave environment with 20nm of crystal size showed higher lifetime than SAPO-34 prepared by conventional hydrothermal method in the reaction of methanol to olefins. It has been found that silicon distribution strongly affects lifetime and selectivity. Thus, silicon at the border of the silicon islands gives higher lifetime and lower C2/C3 ratio. This change in activity and selectivity is better explained in terms of different silicon distribution than on preferential diffusion of ethene through the 8MR pores and agrees with transition-state selectivity. The effects of equilibrium of olefins and deactivation by coke were isolated, showing that after full formation of hydrocarbon pool, selectivity is independent of deactivation by coke.
\end{abstract}

\title{
Keywords
}

Methanol conversion, SAPO-34, deactivation, shape selectivity.

\section{Introduction}

The development of shale gas has decreased the price of natural gas and has renewed the interest in transforming methane into alcohols and olefins that can be used for the production of clean fuels and chemicals ${ }^{1}$. Alcohols can be converted to gasoline range hydrocarbons or short olefins depending mainly on the nature of the catalyst used and, among the short olefins, propylene has shown a growing demand in the past years mainly for the polypropylene industry. Catalyst based on zeolites ZSM-5 and the 
silicoaluminophosphate molecular sieve SAPO-34 are being industrially used for the conversion of methanol into olefins and more specifically into propylene and ethylene ${ }^{2}$.

While the selectivity of SAPO-34 when reacting methanol can be tuned to increase propylene by changing catalyst composition and process variables, extending lifetime as much as possible has still to be improved since it will greatly increase the profitability of the process. Following this, effort has been done in the case of ZSM-5 to decrease the rate of deactivation and its lifetime has been extended by increasing mesoporosity while preserving the micropore of the zeolite. This has been achieved by several procedures such as desilication ${ }^{3-5}$, nanosheets of $\mathrm{ZSM}-5^{6}$ or by co-templating with carbon black or other organics ${ }^{7,8}$. Some methods have been shown more efficient than others since besides active site accessibility and enhanced diffusion of product, the formation of internal defects should be minimized. In summary it was shown that when diffusion of reactants and products is facilitated by generating mesopores, coking is slowed down and lifetime increases. A similar result was obtained when small crystallites or nanosized particles of ZSM-5 have been used ${ }^{9,10}$.

When similar methods for developing mesoporosity have been translated to SAPO-34 and other 8MR zeolites, the expected increase in lifetime was not always attained. Sommer et al, could not improve the lifetime of SSZ-13(CHA) by basic treatments ${ }^{11}$. On the contrary, the addition of co-templates like silanes or surfactants did obtain an increase in mesoporosity and lifetime for SSZ-13 ${ }^{12,13}$ and recently the addition of carbon nanotubes to the synthesis gel also succeeded ${ }^{14}$. An increase in rate of diffusion can be achieved by preparing CHA type materials with smaller crystalline size. For doing that, a dry gel synthesis method ${ }^{15}$, the use of a combination of different SDA ${ }^{16-19}$, as well as the use of microwaves ${ }^{20,21}$ has been applied to the synthesis of SAPO-34 with the objective of enhancing lifetime of the catalyst for the reaction of methanol to 
olefins. It has been found that a combination of TEAOH and morpholine in the synthesis results in a decrease of the size of the crystals with the corresponding increase in lifetime ${ }^{17}$. Wang ${ }^{18}$ also studied the combination of TEA and TEAOH with an improvement in lifetime, and very recently Alvaro-Muñoz et al. ${ }^{19}$ compared different SDA and remarked the importance that high external surface, smaller crystal size and high acidity have for the lifetime of SAPO-34. Hirota et al. ${ }^{15}$ obtained nanocrystals of SAPO-34 of around 75nm by a dry gel synthesis method extending lifetime in the reaction of methanol. Yang et al. ${ }^{22}$ also demonstrated nanosize-enhanced lifetime of SAPO-34 in MTO reactions by investigating the SAPO-34's with different crystallite sizes varying from $80 \mathrm{~nm}$ to $8 \mu \mathrm{m}$ synthesized from the gel with the same composition using TEAOH as SDA.

Since it is clear the benefit of a higher external surface on the lifetime of SAPO-34 for the MTO reaction, that can be easily achieved by synthesizing nanosized SAPO-34 samples for which the contribution of the external to the total surface is very important. In this work we have synthesized nanosized samples of SAPO-34 following the microwave method reported by Lin et al. ${ }^{20}$ and have studied the activity, lifetime and selectivity in the reaction of methanol to olefins. The catalytic performance and stability of nanoSAPO-34 has been compared with other samples of SAPO-34 synthesized by conventional hydrothermal methods using a mixture of morpholine and TEAOH as structure directing agents, which has been reported to also give small crystal size ${ }^{17}$. We have observed that the selective hydrolysis changes the distribution of silicon species after continuous exposure of calcined SAPO-34 samples to moisture, and it affects the activity, selectivity and deactivation behavior of nanosized and conventional samples. We will discuss whether the selectivity of the MTO reaction is affected by product or 
transition-state selectivity and we will clearly separate the effects of crystal size, silicon distribution, hydrocarbon pool and equilibrium of olefins in the overall selectivity.

\section{Experimental.}

\subsection{Synthesis of materials}

SAPO-34 was synthesized by microwave heating as reported by Lin et al. ${ }^{20}$. The composition of the synthesis gel was $1 \mathrm{Al}(\mathrm{OPri})_{3}: 2 \mathrm{H}_{3} \mathrm{PO}_{4}: 0.3 \mathrm{SiO}_{2}: 2$ TEAOH: 30 $\mathrm{H}_{2} \mathrm{O}$. Aluminum isopropoxide $\mathrm{Al}(\mathrm{OPri})_{3}$ was firstly mixed with TEAOH solution (35 wt\%, Aldrich) and deionized water at room temperature until it was dissolved completely. Tetraethylorthosilicate was then added as the silica source and stirred for 2h. Finally, phosphoric acid (85 wt\% in water, Aldrich) was dispersed slowly into the above solution. The reaction mixture was further stirred for $1 \mathrm{~h}$ and then transferred into a Teflon autoclave. The crystallization was conducted in a microwave oven (Milestone ETHOS-D) with pre-programmed heating profiles at $180^{\circ} \mathrm{C}$ for $1 \mathrm{~h}$. The product was separated by high speed centrifugation, washed thoroughly with deionized water and ethanol, and then dried overnight at $50^{\circ} \mathrm{C}$. The as-synthesized crystals were calcined at $550^{\circ} \mathrm{C}$ in air for $6 \mathrm{~h}$ to remove the template molecules. This sample will be called nanoSAPO-34. For comparison purposes, a second sample of SAPO-34 was synthesized following a hydrothermal method, with a mixture of morpholine and TEAOH 1:1 $\mathrm{mol} / \mathrm{mol}$ as SDA with a gel composition of $1 \mathrm{Al}_{2} \mathrm{O}_{3}: 2.12 \mathrm{H}_{3} \mathrm{PO}_{4}: 1.08 \mathrm{SiO} 2$ : 2.09SDA : 66 H2O. First, distilled water was mixed with phosphoric acid and then pseudoboehmite (Merck 85\%) was added slowly, while stirring, and it was further stirred for 7 hours. This resultant solution is named solution A. Fumed silica (Degussa Aerosil-200 99\% SiO2) and morpholine (Aldrich 99\% C4H9O) were mixed thoroughly with water, and formed solution B. Solution B was added dropwise to solution A while 
stirring and then maintained for 7 hours. The resultant product was introduced into a $150 \mathrm{~mL}$ Teflon-lined autoclave and heated at $200^{\circ} \mathrm{C}$ under autogenous pressure for 24 hours. This sample will be called standard-SAPO-34.

\subsection{Characterization.}

The crystallinity of the samples was followed by X-ray powder diffraction (XRD) with a Panalytical CUBIX diffract meter with monochromatic $\mathrm{CuK} \alpha 1,2$ radiation ( $\lambda=1.5406,1.5444 \AA ; \mathrm{K} \alpha 2$ / K $\alpha 1$ intensity ratio=0.5). The morphology and particle size of the zeolite were characterized by Scanning Electron Microscope (SEM, JEOL JSM6300) and Transmission Electron Microscopy. Elemental composition was determined by inductively coupled plasma atomic absorption spectroscopy (ICP-OES) using a Varian 715-ES. The BET surface area, micropore volume and pore volume distribution were measured by $\mathrm{N}_{2}$ adsorption and desorption in a Micromeritics ASAP2000. Lowtemperature infrared spectroscopic (FTIR) experiments were performed in a Bio-Rad FTS-40A spectrometer using, respectively, a homemade stainless steel cell and a quartz cell fitted with KRS-5 windows, both connected to a vacuum dosing system. Before each experiment, the catalysts were pressed into self-supported wafers $(5-10 \mathrm{mg} / \mathrm{cm} 2)$ degassed under vacuum (ca. 10-5 mbar) at $673 \mathrm{~K}$ and then cooled down to RT under vacuum. For low-temperature CO adsorption experiments, the samples were cooled to $77 \mathrm{~K}$ followed by CO dosing at increasing pressure (0.4-8.5 mbar) and recording the IR spectrum after each dosage. After CO dosing, the samples were evacuated and the spectra collected. $\mathrm{NH}_{3}$-TPD experiments were carried out in a Micromeritics 2900 apparatus. A calcined sample (100 mg) was activated by heating to $400^{\circ} \mathrm{C}$ for $2 \mathrm{~h}$ in an oxygen flow and for $2 \mathrm{~h}$ in argon flow. Subsequently, the samples were cooled to $176^{\circ} \mathrm{C}$, and $\mathrm{NH}_{3}$ was adsorbed. The $\mathrm{NH}_{3}$ desorption was monitored with a quadrupole mass 
spectrometer (Balzers, Thermo Star GSD 300T) while the temperature of the sample was ramped at $10^{\circ} \mathrm{C}$ min- 1 in helium flow. Total ammonia adsorption was measured by repeated injection of calibrated amounts of ammonia at $176^{\circ} \mathrm{C}$ until saturation. Ammonia desorption was recorded by means of the mass 15, since this mass is less affected by the water desorbed.

\subsection{Catalytic experiments}

The catalyst was pelletized, crushed and sieved into 0.2-0.4 mm particle size. 50 mg of sample were mixed with 2 g quartz (Fluka) before being introduced into the reactor. Flowing of $\mathrm{N}_{2}(19 \mathrm{~mL} / \mathrm{min})$ was bubbled in methanol at $25^{\circ} \mathrm{C}$, giving a WHSV $=7 \mathrm{~h}^{-1}$. The catalyst was first activated with a nitrogen flow of $80 \mathrm{~mL} / \mathrm{min}$ for $1 \mathrm{~h}$ at $540^{\circ} \mathrm{C}$, and then the temperature was decreased to reaction conditions $\left(400^{\circ} \mathrm{C}\right)$. Each experiment was analyzed with an online gas chromatograph (BRUKER 450GC, with PONA and $\mathrm{Al}_{2} \mathrm{O}_{3}$-Plot capillary columns, and two FID detectors). After reaction, the catalyst was regenerated at $540^{\circ} \mathrm{C}$ in $80 \mathrm{ml}$ of air for $3 \mathrm{~h}$ and the reaction was repeated again. Preliminary experiments were carried out at constant WHSV, different amount of catalyst and increasing flow rates, and later with catalyst with in different particle sizes, to check that, at the selected reaction conditions the process is not controlled by either external or intraparticle diffusion. Conversion and selectivities were considered in carbon basis and methanol and dimethylether were lumped together for calculation of conversion.

\section{Results and discussion}

\subsection{Catalyst characterization}


XRD of nano and standard-SAPO-34 samples are shown in Figure 1 after exposure to room conditions for 1 to 42 days, being therefore in contact with air with $40-60 \%$ moisture. The nano-SAPO-34 sample presents as expected, a diffraction pattern with very low resolution due to the small size of the crystals and there is no indication of any decrease in intensity after exposition at room conditions during the period of exposure. The standard-SAPO-34 shows a diffraction pattern more intense and also there is no modification after the same period of exposure to moisture. ICP analysis of calcined samples determined a bulk molar composition of $\mathrm{Al}: \mathrm{Si}: \mathrm{P}=1: 0.31: 0.73$ and 1:0.91:0.66 for nano-SAPO-34 and standard-SAPO-34 respectively.

Fig. 2 shows the SEM and TEM images of nano-SAPO-34 prepared by microwave heating and the standard-SAPO-34. The nano-SAPO-34 sample shows spherical aggregates of 150-300 nm formed by smaller crystals of around 20-50 nm, while standard-SAPO-34 presents cubic crystals of $\sim 300-600 \mathrm{~nm}$. The smaller dimensions of the crystals of nano-SAPO-34 are consistent with the broad XRD peaks shown in Figure 1, and the size of standard-SAPO-34 is in agreement with the examples reported by Lee et $\mathrm{al}^{17}$, in which SAPO-34 synthesized with the same mixture 1:1 of morpholine and TEAOH also presented crystal size in sub-micrometer range.

The textural properties measured by adsorption of nitrogen of the two SAPO-34 samples are shown in Table 1. Nano-SAPO-34 shows very high external surface of 231 $\mathrm{m}^{2} \mathrm{~g}^{-1}$ area as a consequence of the small size of the crystals. In fact, the adsorptiondesorption isotherm for nano-SAPO-34 (Fig. 3) shows a strong increase in adsorption with hysteresis at high relative pressures due to the intercrystalline porosity typical of nanocrystalline materials. After contact with ambient moisture for up to 107 days, the micropore volume steadily decreases while external surface area seems not to be affected (Fig. S1). On the contrary, standard-SAPO-34 presents a lower external and 
BET surface area which does not seem to be affected after 2 months of exposure to moisture (Fig. S2).

The coordination of $\mathrm{Al}, \mathrm{P}$ and $\mathrm{Si}$ atoms in SAPO-34 was studied by ${ }^{27} \mathrm{Al},{ }^{31} \mathrm{P}$ and ${ }^{28} \mathrm{Si}$ MAS NMR. The ${ }^{27} \mathrm{Al}$ MAS NMR spectra are given in Figure 4. Calcined nanoSAPO-34 shows an intense peak at 36 ppm followed by other signals at -11 and 14 ppm, that corresponds to tetrahedrally coordinated aluminum in local structures of $\mathrm{Al}(\mathrm{PO})_{4}$, and octa and pentacoordinated aluminum, respectively ${ }^{23}$. After 7 days of storage, the signal at 14 ppm continuously increased indicating hydration of $\mathrm{Al}(\mathrm{PO})_{4}$ species $^{23,}{ }^{24}$, while the signal of tetracoordinate aluminum is shifted to $-41 \mathrm{ppm}$. The shifting of the tetrahedral signal could be attributed to a distortion of the framework due to the hydration of the structure ${ }^{25}$. The standard-SAPO-34 sample shows the same signals, with a lower intensity of octahedral aluminum, possibly due to a lower effect of hydration that is accompanied with a lower shifting of the tetrahedral signal at 36ppm. When both hydrated samples were dehydrated in vacuum at $200^{\circ} \mathrm{C}$, the initial ${ }^{27} \mathrm{Al}$ MAS NMR spectra was recovered only for standard-SAPO-34, indicating the irreversibility of the hydration process of nano-SAPO-34.

The ${ }^{29}$ Si MAS NMR spectra of nano and standard-SAPO-34 is shown in Figure 5. This technique is useful to study the mechanism of silicon incorporation in the framework of $\mathrm{AlPO}_{4}$. In silicoaluminophosphates, silicon is incorporated following two different mechanisms, SM2 in which a single Si substitutes a single P atom, or SM3 in which two Si atoms substitute two neighbours $\mathrm{Al}$ and $\mathrm{P}$ atoms ${ }^{26,27}$. Nano-SAPO-34 shows a broad signal formed by components at $-89,-95,-100,-105$ and $-110 \mathrm{ppm}$, that correspond to $\mathrm{Si}(4 \mathrm{Al}), \mathrm{Si}(3 \mathrm{Al}), \mathrm{Si}(2 \mathrm{Al}), \mathrm{Si}(1 \mathrm{Al})$ and $\mathrm{Si}(0 \mathrm{Al})$ respectively ${ }^{25,27-29}$. The incorporation of silicon through SM2 generates Si4Al groups while mechanism SM3 generates the others. It appears then that in the nano-SAPO-34 sample there is an 
important contribution of the SM3 substitution mechanism. By performing the deconvolution of the different silicon signals (Table 2) it can be observed that after 7 days of hydration, the signal at $-95 \mathrm{ppm}$ corresponding to $\mathrm{Si}(3 \mathrm{Al})$ and also the signal at 110 (Si0Al) decrease while a broad small band around -78 to -85 appears. This broad band has been assigned to $\mathrm{Q}^{1}, \mathrm{Q}^{2}$, and $\mathrm{Q}^{3}$ Si species ( $\left.\left.\mathrm{Si}(\mathrm{OT}) \mathrm{n}\right) \mathrm{OH}\right)_{4-n}$ ) due to hydration at room temperature and breaking of $\mathrm{Si}-\mathrm{OH}-\mathrm{Al}$ bonds ${ }^{30}$, disordered $\mathrm{Si}(4 \mathrm{Al}){ }^{23}$ or partially hydrated Si species located at the edge of a Si domain ${ }^{31}$.We have seen that the intensity of this band is enhanced by $\mathrm{H}$ cross-polarization ${ }^{30,31}$, suggesting that it corresponds to $\mathrm{Si} 3 \mathrm{AlOH}$ or defect Si sites. Therefore, it appears that $\mathrm{Si}(3 \mathrm{Al})$ species are first affected by hydrolysis creating groups $\mathrm{Si}(\mathrm{OAl})(3-\mathrm{x})(\mathrm{SiOH}) \mathrm{x}$. It is important to note that silicon species incorporated by SM3 mechanism are first affected by hydrolysis, because their associated brönsted acid sites are stronger than those generated by single Si incorporation (SM2). In fact, recently Katada et al. ${ }^{32}$ studied different SAPO-34 and determined that samples with less isolated Si presented weaker brönsted acidity and attributed the stronger acidity to the presence of distorted structure including $\mathrm{SiO} 2$ islands or defects. Other authors ${ }^{28,33,34}$, assign the higher acidity of some SAPOs to the presence of silicon islands in which acid sites are generated at the borders, and correspond to (Si3Si1Al), which would be the strongest acid sites. Consequently, in our case for nano-SAPO-34 the silicon species first affected by hydrolysis are those that generate stronger acid sites and then, the overall acidity should be decreased by hydrolysis and the acid strength will be shifted to milder acidities. The standard-SAPO34 sample shows sharper signals of ${ }^{29} \mathrm{Si}$ MAS NMR at the same positions that nanoSAPO-34, with higher intensity of the signals at -105 and -110 corresponding to $\mathrm{Si}(1 \mathrm{Al})$ and $\mathrm{Si}(\mathrm{OAl})$ due to its higher silicon content. However, the changes after several days of hydration are slower. After 32 days of hydration the signal at -95 ppm corresponding to 
$\mathrm{Si}(3 \mathrm{Al})$ starts to decrease, and only after 40 days, the signal of defects from the signals at -78 to -85 ppm are visible. Again, the standard-SAPO-34 is shown less sensitive to hydrolysis than nano-SAPO-34.

The ${ }^{31} \mathrm{P}$ NMR spectra (Fig. 6) for fresh nano-SAPO-34 shows an asymmetrical signal at $-30 \mathrm{ppm}$ corresponding to tetrahedral $\mathrm{P}(\mathrm{OAl})_{4}$. After 7 days of hydration another signal at $-16 \mathrm{ppm}$ appears corresponding to $\mathrm{P}$ atoms coordinated with water molecules in form of species $\mathrm{P}(\mathrm{OAl}) \mathrm{x}(\mathrm{H} 2 \mathrm{O}) \mathrm{y}^{23,35,36}$. The relative intensity of the signal at $-16 \mathrm{ppm}$ increased continuously even up to 42 days of hydration and correlates well with the increase in the octahedral signal of ${ }^{27} \mathrm{Al} \mathrm{NMR}$ at -12ppm which was assigned to the hydration of the $\mathrm{Al}(\mathrm{PO})_{4}$ species. In the case of the standard SAPO-34 sample, the only signal that appears is the one corresponding to tetrahedral phosphorus at - $30 \mathrm{ppm}$ up to 40 days of hydration.

The FTIR spectrum of nanoSAPO-34 in the hydroxyl region is shown in Fig. 7. The sample nano-SAPO-34 shows characteristic signals at 3600 and $3630 \mathrm{~cm}^{-1}$ assigned to low and high-frequency Brönsted $\mathrm{OH}$ groups, 3745 and $3678 \mathrm{~cm}^{-1}$ which correspond to external Si-OH and P-OH groups respectively. Two more signals are visible at 3796 and $3770 \mathrm{~cm}^{-1}$ which are assigned to $\mathrm{OH}$ groups linked to tetrahedral $\mathrm{Al}^{37,38}$. The relatively high intensity of these latter two bands must be assigned to the high external surface of the sample. In addition, there is a broad band centered around 3400-3500 $\mathrm{cm}^{-1}$ which probably corresponds to $\mathrm{Si}-\mathrm{OH}$ and $\mathrm{P}-\mathrm{OH}$ groups in different interacting through $\mathrm{H}$-bonds, as reported for high silica CHA zeolites ${ }^{39}$ and mesoporous AlPO ${ }^{40}$. After several days of hydration this broad band increases in intensity indicating that defects are being formed. In addition, the band at $3678 \mathrm{~cm}-1$ corresponding to $\mathrm{P}-\mathrm{OH}$ groups also increases due to the irreversible hydrolysis of some Al-O-P bonds. 
The adsorption of $\mathrm{CO}$ at low temperatures has been used to characterize the strength of the acid sites of SAPO-34. In the case of nano-SAPO-34 (Fig. 8), the bands corresponding to HF and LF brönsted acid sites are shifted after adsorption and interaction of bridging hydroxyl groups with CO to a broad band around $3200-3500 \mathrm{~cm}^{-1}$ which is in agreement with that reported in the literature ${ }^{28,41}$. The broad band around $3200-3500 \mathrm{~cm}^{-1}$ is composed of a main signal at $3364 \mathrm{~cm}^{-1}$ and a shoulder at $3474 \mathrm{~cm}^{-1}$. These signals have been assigned to $\mathrm{CO}$ interacting with $\mathrm{HF}$ and LF hydroxyls and, in agreement with the work of Martins et al ${ }^{28}$. By deconvolution of the broad IR band, other band at $3280 \mathrm{~cm}^{-1}$ is required. Due to its larger shift and according to ref. data ${ }^{28}$, this band at $3280 \mathrm{~cm}^{-1}$ has been assigned to $\mathrm{CO}$ interacting with acid sites corresponding to $\mathrm{Si}$ in the borders of the silicon islands, and which have a stronger acidity. As shown above in the analysis of SiNMR spectra, after days of hydration of nano-SAPO-34 it was expected to see a decrease of those sites of higher strength as shown by $\mathrm{CO}$ adsorption if they are related to Si(3Si1Al). However, the fitting process for deconvolution of the overlapped bands showed a contribution of the $3280 \mathrm{~cm}^{-1}$ band of around $10 \%$ of the overall area of the broad band, being almost impossible to distinguish if there is a decrease in the concentration of these sites due to hydrolysis and transformation in defects. In the CO stretching vibration region a band at $2171 \mathrm{~cm}^{-1}$ appears after $\mathrm{CO}$ adsorption (Fig. 9), corresponding to $\mathrm{CO}$ interacting with Brönsted acid sites ${ }^{42}$. The position of this band is the same for the different nano-SAPO-34 hydrated samples. Therefore, by adsorption of CO we could not found any evidence of different acid strength of the nano-SAPO-34 samples after hydration.

In summary from the characterization results, it has been shown that nano-SAPO-34 
presents much lower crystal size and therefore more external surface area than standardSAPO-34. As a consequence, the structure of nano-SAPO-34 has been shown very sensitive to moisture, with a change in the distribution of silicon species, in which at short range of time, a clear decrease in the ${ }^{29} \mathrm{Si}$ MAS NMR assigned to $\mathrm{Si}$ on the edge of the $\mathrm{Si}$ islands indicates a selective hydrolysis of these $\mathrm{Si}-\mathrm{O}-\mathrm{Al}$ bonds. From these results, it is expected that nano-SAPO-34 presents higher lifetime in the reaction of methanol in which selectivity to products should depend on the different distribution of silicon species.

\subsection{Catalytic experiments}

\subsubsection{Activity and kinetic analysis.}

The activity of nano and standard-SAPO-34 is shown in Figure 10 at WHSV=7 h ${ }^{-1}$. It is important to note that lifetime of nano-SAPO-34 and standard-SAPO-34 are very similar when the samples are freshly calcined. However, in the case of nano-SAPO-34, lifetime changes with time of storage and exposure to moisture at room temperature. First, the activity increases up to 14 days of storage and then decreases continuously. StandardSAPO-34 showed always lower lifetime changes than of nano-SAPO-34, and activity seems to stabilize after 42 days of storage. In order to rationalize the different behavior of activity for the of SAPO-34 samples, we have performed a kinetic analysis following the model proposed by Janssens ${ }^{43}$ for the deactivation of ZSM-5 during conversion of methanol to gasoline. Jannsens proposes that conversion of methanol to hydrocarbons on zeolites can be modeled with a kinetic equation that includes only two parameters, the rate constant and the deactivation coefficient, assuming a first order of reaction and a 
deactivation rate proportional to the conversion. Also by following this methodology, half lifetime and conversion capacity of methanol, that is the amount of methanol that can be converted before full deactivation, can easily be estimated (Table 4). The model proposed by Janssens considers deactivation as an effective decrease of contact time, and agrees with a "non selective deactivation" of the reaction, in which the successive steps from reactants to products are affected by deactivation at the same rate and can be modeled by a single parameter. The model reproduces quite well the oligomerization of olefins, as well as the reaction of methanol to gasoline in ZSM-5 ${ }^{44,45}$. However, the reaction of methanol to olefins on SAPO-34 was shown by Chen et al ${ }^{46,47}$ to follow a "selective deactivation". In our case, the fitting of the conversion of methanol+dimethylether lumped for both SAPO34 samples is surprisingly as good as the fitting reported with ZSM-5 suggesting that a "single event kinetics model" can also be used with SAPO-34 as in the case of ZSM-5. In addition, the selectivity at three different spatial times were compared in Figure S3, and it was shown that the selectivities are very similar at constant conversion and do not depend on spatial time. So, also in SAPO-34 as it occurs when the catalyst was ZSM-5, deactivation can be considered as "a decrease of contact time", that at the end is equivalent to say a decrease in the amount of active catalyst during time on stream. Then, by fitting the following model in where: $\mathrm{X}=$ conversion, tau=spatial time gcat $/ \mathrm{mol} \mathrm{h}$, a is the deactivation constant, $\mathrm{K}$ is the kinetic rate constant, the values of the kinetic rates and deactivation constants are given in table 5 .

$\frac{d X}{d t}=k(1-X)$ 


$$
\begin{aligned}
& \frac{d \tau}{d t}=-a X \\
& X=\frac{\left(\exp \left(k \tau_{0}\right)-1\right) \exp (-k a t)}{1+\left(\exp \left(k \tau_{0}\right)-1\right) \exp (-k a t)}
\end{aligned}
$$

It can be seen there that the initial kinetic rate constant is much higher for nanoSAPO-34 than for the standard sample. This would agree with the smaller size of the crystals of nano-SAPO-34, since methanol reaction on eight member ring zeolites is controlled by diffusion within the micropore and a catalyst with a higher external surface should increase initial activity. Moreover, taking into account that both samples presented similar acidity measured by ammonia-TPD (Table 3), the kinetic rate constant obtained must be directly related to the number of accessible sites close to the surface of the catalyst. After exposure to moisture at room temperature the kinetic rate constant steadily decreases in both nano and standard-SAPO-34. The initial deactivation constant is similar for both catalysts. However its behavior after exposure to moisture at room atmosphere is different. In the case of nano-sapo-34, the deactivation constant strongly decreases up to 14 days and then increases, while for standard-SAPO-34 it continuously increases. The longterm increase in the deactivation constant could be due to the presence of defects created by the irreversible hydrolysis of the structure, as shown above by FTIR and NMR, that could accelerate deactivation by adsorption of coke precursors. In fact, a higher deactivation and shorter lifetime was reported in the case of zeolite ZSM-5, in which the creation of internal silanol nests by carbon templating induced higher deactivation in the MTH reaction ${ }^{48,49}$. On the other hand, the short-term decrease in the deactivation constant until the $14^{\text {th }}$ day of exposure for nano-SAPO-34 could be attributed to the hydrolysis of 
the Si-O-Al groups at the border of the silicon islands shown before by NMR. These acid sites are believed to present strong acidity and which will promote coking faster than single silicon sites in SAPO-34. The disappearance by hydrolysis of the very strong acid sites would enhance lifetime. Therefore by selective hydrolysis of Si-O-Al bonds corresponding to the strongest acid sites, the remaining acidity makes a catalyst with lower deactivation rate and longer lifetime.

\subsubsection{Shape-selectivity and thermodymanic equilibrium of olefins}

When selectivities to olefins are plotted vs. conversion (Fig. 11, and S4,S5), in general, selectivity is constant when conversion is not complete, and changes with time on stream when regarded at full conversion. As a consequence, the $\mathrm{C} 2 / \mathrm{C} 3$ ratio tends to increase with time on stream (Fig. 12). This was already described by several authors and Chen et al. ${ }^{50}$ showed that ethylene selectivity increases when increasing coke and proposed that coke has an effect for the effective reduction of void volume of the cavities modifying the transition-shape selectivity by favoring the formation of smaller molecules. On the other hand Dahl ${ }^{51}$ and Barger ${ }^{52}$ have proposed that it is a product shape selectivity effect the one that controls product distribution and that higher ethylene selectivity is due to a faster diffusion of the shorter ethylene vs. the longer propylene through 8MR windows. The latter proposition was supported by Hereijgers et al. ${ }^{53}$ who, by means of isotopic experiments with ${ }^{13} \mathrm{C}$-marked methanol, claimed hexamethylbenzene as the most active intermediate for the MTO reaction, being this independent of the amount of coke 
formed. However, if an easier diffusion of ethylene was the main factor affecting the ratio C2/C3 with time on stream, this ratio should be greatly affected by the size of the crystal of SAPO-34 and higher C2/C3 value would be expected with larger zeolite crystals. When looking into the C2/C3 ratio of nano and standard-SAPO-34, one can observe that the trend is the opposite, i.e. C2/C3 is higher for nano-SAPO-34 and increases with TOS. Moreover, when the samples are aged at room conditions the C2/C3 ratio decreases. Taking into account the effect of zeolite crystallite size and the effect of moisture on the $\mathrm{C} 2^{\prime} \mathrm{C} 3$ ratio in the present work, we cannot support the hypothesis that a higher C2 selectivity is due to differences in diffusion between C2 and C3 through the 8-ring pores. We believe that the results obtained could be better explained on the bases of acid strength than on the bases of diffusion. In fact, Song et al. ${ }^{54}$ have reported that the selectivity of ethylene was favoured by methylbenzenes trapped in the cages with lower number methyl groups, while propylene is favoured when the number of methyl groups is higher. Also Arstad et al. ${ }^{55}$ showed that the formation of ethylene from either hexa or tetramethylbenzene reaction center is energetically less favoured than propylene. So, it can be deduced that stronger acidities should induce higher $\mathrm{C} 2 / \mathrm{C} 3$ ratios. In the case of fresh nano-SAPO-34, the presence of strong acid sites related to Si located at the border of silicon islands, could then be the reason of the higher $\mathrm{C} 2 / \mathrm{C} 3$ ratio observed with this sample. Then, when the number of these sites is reduced by hydrolysis at room atmosphere, the C2/C3 ratio drops sensibly.

The variation of the C2/C3 ratio with Time on Stream is restricted to the analysis in which conversion is close to $100 \%$ and it seems logical to think that thermodynamic equilibrium between olefins should be approached with the corresponding effect on 
selectivity. In Table 5, initial and "steady-state selectivity" are compared with thermodynamic values calculated including or not branched C4 and C5 olefins. It is important to notice that the branched olefins obtained in the case of nano-SAPO-34 must be attributed to reactions occurring at the external surface area which, in this case is much larger. When branched olefins were included in the thermodynamic calculations a distribution of C2/C3 a different of equilibrium, with lower amounts of C2-C3 olefins were observed. In fact, the initial distribution of olefin in both SAPO-34 correlates with the different equilibrium distribution, with the exception of ethylene. This is not surprising taking into account that in the transformation of different olefins, ethylene is very difficult to activate or protonate comparing with longer olefins. Similar results were obtained by Zhou et al ${ }^{56}$ showing that the rate of conversion of ethylene on SAPO-34 is much lower than propylene and butene. In summary, at the start of the reaction, after the induction period, the olefins formed at the top of the bed are transformed along the catalytic bed with the fresh catalyst towards the equilibrium distribution. Then, in the case of nano-SAPO-34 with higher external surface, olefins can further isomerize, and branched C4 and C5 products appear as products. As the deactivation front moves through the catalyst bed, less fresh catalyst remains until breakthrough of conversion below $100 \mathrm{wt} \%$, from where the selectivity reaches a steady-state, less affected by interconversion of olefins and approaching the original selectivity of the hydrocarbon pool (Fig. 13).

Very recently Chen et al. ${ }^{57}$ proposed that at the beginning of the reaction, when low coke is formed in the cavities and not any methylated benzyl cation has been formed yet, the olefinic part of the "dual cycle mechanism" in which olefins follows a methylation- 
cracking mechanism is already working, resulting in low selectivity to ethylene. In our case, it is hard to think that for more than two hours the selectivity in nano-SAPO-34 is mainly governed by the olefin cycle. This would assume that the rate of cyclization and hydrogen transfer of olefins to aromatics in the cages is very much slower than the rate of methylation-cracking. In addition, the presence of branched C4 and C5 in the reaction on nano-SAPO-34 indicates that thermodynamic equilibrium of olefin is greatly affecting selectivity at high conversion values.

Therefore, while conversion during MTO reaction on SAPO-34 is close to $100 \%$, which is the working parameter for the industrial unit, the selectivity to olefins is strongly affected by thermodynamic distribution. In addition, the differences in C2/C3 ratio after exposition to moisture, and also the comparison with the values obtained with the largersized Standard-SAPO-34 do not correlate with an easier diffusion of ethylene vs. propylene. Moreover, this result is more in agreement with "transition selectivity effect" in which distribution of products is affected by different silicon distribution or different acid properties of the catalyst and not to a "product shape selectivity" in which coking reduces the size of the cages and hinders diffusion of products. Recently, Wang et al. ${ }^{58}$ have proposed by DFT calculations that olefins themselves are likely the dominating hydrocarbon pool species on SAPO-34, and that ethene and propene are produced through the cracking of $\mathrm{C}^{+}+$and $\mathrm{C}^{+}+$ions. Our experimental results cannot support this. If the olefin cycle were so predominant and only the cracking of carbenium ions influences selectivity, the distribution of products would be governed by thermodynamic distribution. However, as we showed above, in the presence of methanol and DME, the selectivity to 
ethene among the olefins is constant and always above thermodynamic equilibrium. Therefore, taking into account the experimental results obtained and assuming that the paring scheme of the hydrocarbon pool is expected to be less predominant in SAPO- $34^{59}$, olefins selectivity should be produced through aromatic intermediates by the side-chain methylation mechanism ${ }^{60}$. These aromatic and positively charged transition states could lead to different selectivities depending on differences in acid strength, as suggested recently by Westgard et al. ${ }^{61}$. In addition, the potential participation of aromatic radical cations, already detected as reaction intermediates ${ }^{62}$, could contribute to lower energy barriers for ethene production than those calculated by previous DFT calculations.

\section{Conclusions}

We have shown that nano sized samples of SAPO-34 synthesized by microwave heating presents much higher lifetime than standard-SAPO-34 synthesized by conventional hydrothermal method for the reaction of methanol to olefins. However the stability of nano-SAPO-34 when exposed to moisture at room conditions is lower than that of the standard-SAPO-34. Firstly, hydrolysis of Si-O-Al bonds of silicon in the border of silicon islands, occurs and since the acid sites corresponding to these Si species are believed to present higher acidity and favor coking and deactivation of the catalyst a decrease in the rate of deactivation of nano-SAPO-34 by coking is observed with sample exposed to moisture up to 14 days. Then, after 14 days, lifetime decreases continuously due to hydrolysis of both Si-O-Al and Al-O-P bonds.

The selectivity to different olefins in the reaction strongly changes for samples of 
nano-SAPO-34 exposed to moisture during a different number of days. The C2/C3 ratio decreases after exposure of the samples to moisture. A higher $\mathrm{C} 2 / \mathrm{C} 3$ ratio is related to a higher population of Si in the border of the Si islands, with acid sites of higher strength. This is in agreement with a "transition-state selectivity effect" in which higher amount distribution of products is affected by different acid properties of the catalyst and not by an "easier diffusion” of ethylene vs. propylene. In addition, the initial olefin distribution is strongly affected by thermodynamic distribution among the two olefins, decreasing the yield of ethylene, which is produced above the equilibrium by the aromatics-based hydrocarbon pool mechanism.

\section{Acknowledgements}

Financial support by the Spanish MINECO (MAT2012-37160, CSD2009-00050CONSOLIDER/INGENIO 2010), and Generalitat Valenciana by the PROMETEO program is acknowledged. Z. Li acknowledges China Scholarship Council (CSC) for a fellowship. J. Yu thanks the support by the State Basic Research Project of China (Grant no. 2011CB808703) and the National Natural Science Foundation of China.

\section{References}

1. Annual Energy Outlook 2012 with Projections to 2035 DOE/EIA-0383(2012), U.S. Energy Information Administration, 2012.

2. M. Stöcker, in Zeolites and Catalysis, Wiley-VCH Verlag GmbH \& Co. KGaA, 2010, pp. 687-711.

3. M. Bjørgen, F. Joensen, M. Spangsberg Holm, U. Olsbye, K. P. Lillerud and S. Svelle, Appl. Catal. A, 
2008, 345, 43-50.

4. P. N. R. Vennestrøm, M. Grill, M. Kustova, K. Egeblad, L. F. Lundegaard, F. Joensen, C. H. Christensen and P. Beato, Catal. Today, 2011, 168, 71-79.

5. K. Barbera, F. Bonino, S. Bordiga, T. V. W. Janssens and P. Beato, J. Catal., 2011, 280, 196-205.

6. K. Na, M. Choi and R. Ryoo, Microporous Mesoporous Mater., 2013, 166, 3-19.

7. C. J. H. Jacobsen, C. Madsen, J. Houzvicka, I. Schmidt and A. Carlsson, J. Am. Chem. Soc., 2000, 122, 7116-7117.

8. J. Kim, M. Choi and R. Ryoo, J. Catal., 2010, 269, 219-228.

9. M. Firoozi, M. Baghalha and M. Asadi, Catal. Commun., 2009, 10, 1582-1585.

10. A. A. Rownaghi and J. Hedlund, Ind. Eng. Chem. Res., 2011, 50, 11872-11878.

11. L. Sommer, D. Mores, S. Svelle, M. Stöcker, B. M. Weckhuysen and U. Olsbye, Microporous Mesoporous Mater., 2010, 132, 384-394.

12. L. Wu, V. Degirmenci, P. C. M. M. Magusin, B. M. Szyja and E. J. M. Hensen, Chem. Commun., 2012, 48, 9492-9494.

13. L. Wu, V. Degirmenci, P. C. M. M. Magusin, N. J. H. G. M. Lousberg and E. J. M. Hensen, J. Catal., 2013, 298, 27-40.

14. F. Schmidt, S. Paasch, E. Brunner and S. Kaskel, Microporous Mesoporous Mater., 2012, 164, $214-$ 221.

15. Y. Hirota, K. Murata, S. Tanaka, N. Nishiyama, Y. Egashira and K. Ueyama, Mater. Chem. Phys., 2010, 123, 507-509.

16. K. Y. Lee, H. J. Chae, S. Y. Jeong and G. Seo, Appl. Catal. A, 2009, 369, 60-66.

17. Y. J. Lee, S. C. Baek and K. W. Jun, Appl. Catal. A, 2007, 329, 130-136.

18. P. Wang, A. Lv, J. Hu, J. Xu and G. Lu, Microporous Mesoporous Mater., 2012, 152, 178-184.

19. T. Álvaro-Muñoz, C. Márquez-Álvarez and E. Sastre, Catal. Today, 2012, 179, 27-34.

20. S. Lin, J. Li, R. P. Sharma, J. Yu and R. Xu, Top. Catal., 2010, 53, 1304-1310.

21. F. M. Shalmani, R. Halladj and S. Askari, Powder Technol., 2012, 221, 395-402.

22. G. Yang, Y. Wei, S. Xu, J. Chen, J. Li, Z. Liu, J. Yu and R. Xu, J. Phys. Chem. C, 2013, 117, 8214-8222.

23. A. Buchholz, W. Wang, A. Arnold and M. Hunger, Microporous Mesoporous Mater., 2003, 57, 157168.

24. A. Buchholz, W. Wang, M. Xu, A. Arnold and M. Hunger, Microporous Mesoporous Mater., 2002, 56, 267-278.

25. C. S. Blackwell and R. L. Patton, J. Phys. Chem., 1988, 92, 3965-3970.

26. B. M. Lok, C. A. Messina, R. L. Patton, R. T. Gajek, T. R. Cannan and E. M. Flanigen, J. Am. Chem. Soc., 1984, 106, 6092-6093.

27. R. Vomscheid, M. Briend, M. J. Peltre, P. P. Man and D. Barthomeuf, J.Phys.Chem., 1994, 98, 96149618.

28. G. A. V. Martins, G. Berlier, S. Coluccia, H. O. Pastore, G. B. Superti, G. Gatti and L. Marchese, J. Phys. Chem. C, 2007, 111, 330-339.

29. Y. Wei, D. Zhang, L. Xu, F. Chang, Y. He, S. Meng, B.-I. Su and Z. Liu, Catal. Today, 2008, 131, 262-269.

30. M. Briend, R. Vomscheid, M. J. Peltre, P. P. Man and D. Barthomeuf, J. Phys. Chem., 1995, 99, 82708276.

31. K. Suzuki, T. Nishio, N. Katada, G. Sastre and M. Niwa, PCCP, 2011, 13, 3311-3318.

32. N. Katada, K. Nouno, J. K. Lee, J. Shin, S. B. Hong and M. Niwa, J. Phys. Chem. C, 2011, 115, 2250522513. 
33. G. Sastre, D. W. Lewis, C. Richard and A. Catlow, J. Phys. Chem. B, 1997, 101, 5249-5262.

34. D. Barthomeuf, Zeolites, 1994, 14, 394-401.

35. A. Buchholz, W. Wang, M. Xu, A. Arnold and M. Hunger, J. Phys. Chem. B, 2004, 108, 3107-3113.

36. Y. Watanabe, A. Koiwai, H. Takeuchi, S. A. Hyodo and S. Noda, J. Catal., 1993, 143, 430-436.

37. G. Busca, V. Lorenzelli, V. S. Escribano and R. Guidetti, J. Catal., 1991, 131, 167-177.

38. G. Busca, V. Lorenzelli, G. Ramis and R. J. Willey, Langmuir, 1993, 9, 1492-1499.

39. E. A. Eilertsen, B. Arstad, S. Svelle and K. P. Lillerud, Microporous Mesoporous Mater., 2012, 153, 94-99.

40. E. Gianotti, V. Dellarocca, E. C. Oliveira, S. Coluccia, H. O. Pastore and L. Marchese, in Stud. Surf. Sci. Catal., eds. G. G. R. Aiello and F. Testa, Elsevier, 2002, vol. Volume 142, pp. 1419-1426.

41. S. Bordiga, L. Regli, D. Cocina, C. Lamberti, M. Bjørgen and K. P. Lillerud, J. Phys. Chem. B, 2005, 109, 2779-2784.

42. F. Bleken, M. Bjørgen, L. Palumbo, S. Bordiga, S. Svelle, K. P. Lillerud and U. Olsbye, Top. Catal., 2009, 52, 218-228.

43. T. V. W. Janssens, J. Catal., 2009, 264, 130-137.

44. D. Chen, H. P. Rebo, K. Moljord and A. Holmen, Ind. Eng. Chem. Res., 1997, 36, 3473-3479.

45. U. Sedran, A. Mahay and H. I. De Lasa, Chem. Eng. Sci., 1990, 45, 1161-1165.

46. D. Chen, H. P. Rebo, K. Moljord and A. Holmen, Stud. Surf. Sci. Catal., 1997, 111, 159-166.

47. D. Chen, H. P. Rebo, K. Moljord and A. Holmen, Ind. Eng. Chem. Res., 1999, 38, 4241-4249.

48. S. Svelle, L. Sommer, K. Barbera, P. N. R. Vennestrøm, U. Olsbye, K. P. Lillerud, S. Bordiga, Y. H. Pan and P. Beato, Catal. Today, 2011, 168, 38-47.

49. P. Sazama, B. Wichterlova, J. Dedecek, Z. Tvaruzkova, Z. Musilova, L. Palumbo, S. Sklenak and O. Gonsiorova, Microporous Mesoporous Mater., 2011, 143, 87-96.

50. D. Chen, A. Grønvold, K. Moljord and A. Holmen, Ind. Eng. Chem. Res.,, 2006, 46, 4116-4123.

51. I. M. Dahl, H. Mostad, D. Akporiaye and R. Wendelbo, Microporous Mesoporous Mater., 1999, 29, 185-190.

52. P. Barger, in Zeolites for Cleaner Technologies (Catalytic Science Series Vol. 3), eds. M. Guisnet and J. P. Gilson, Imperial College Press, London, 2002, vol. 3, pp. 239-260.

53. B. P. C. Hereijgers, F. Bleken, M. H. Nilsen, S. Svelle, K. P. Lillerud, M. Bjørgen, B. M. Weckhuysen and U. Olsbye, J. Catal., 2009, 264, 77-87.

54. W. Song, H. Fu and J. F. Haw, J. Am. Chem. Soc., 2001, 123, 4749-4754.

55. B. Arstad, J. B. Nicholas and J. F. Haw, J. Am. Chem. Soc., 2004, 126, 2991-3001.

56. H. Zhou, Y. Wang, F. Wei, D. Wang and Z. Wang, Appl. Catal. A, 2008, 348, 135-141.

57. D. Chen, K. Moljord and A. Holmen, Microporous Mesoporous Mater., 2012, 164, 239-250.

58. C. M. Wang, Y. D. Wang and Z. K. Xie, J. Catal., 2013, 301, 8-19.

59. C. M. Wang, Y. D. Wang, Z. K. Xie and Z. P. Liu, J. Phys. Chem. C, 2009, 113, 4584-4591.

60. K. Hemelsoet, J. Van der Mynsbrugge, K. De Wispelaere, M. Waroquier and V. Van Speybroeck, ChemPhysChem, 2013, DOI: 10.1002/cphc.201201023.

61. M. Westgård Erichsen, S. Svelle and U. Olsbye, Catal. Today., 2013, DOI: 10.1016/j.cattod.2013.03.017

62. S. J. Kim, H. G. Jang, J. K. Lee, H. K. Min, S. B. Hong and G. Seo, Chem. Commun., 2011, 47, 94989500.

63. J. M. Smith, H. C. Van Ness and M. M. Abbott, Introduction to chemical engineering thermodynamics, 7th edn., McGraw-Hill, Boston, 2005. 
64. R. A. Alberty and C. A. Gehrig, J. Phys. Chem. Ref. Data, 1985, 14, 803-820. 
Table 1. Textural properties of nano and standard-SAPO-34 samples after days of exposure to moisture.

\begin{tabular}{lcccc}
\hline Sample & $\begin{array}{c}\mathrm{BET} \\
\left(\mathrm{m}^{2} / \mathrm{g}\right)\end{array}$ & $\begin{array}{c}\mathrm{t}-\mathrm{plot} \mathrm{S}_{\text {ext }} \\
\left(\mathrm{m}^{2} / \mathrm{g}\right)\end{array}$ & $\begin{array}{c}\mathrm{V}_{\text {micro }} \\
\left(\mathrm{cm}^{3} / \mathrm{g}\right)\end{array}$ & $\begin{array}{c}\mathrm{V}_{\text {meso }} \\
\left(\mathrm{cm}^{3} / \mathrm{g}\right)\end{array}$ \\
\hline Nano-SAPO-34-1day & 646 & 231 & 0.20 & 0.21 \\
Nano-SAPO-34-7days & 639 & 226 & 0.20 & 0.21 \\
Nano-SAPO-34-14days & 616 & 224 & 0.19 & 0.20 \\
Nano-SAPO-34-28days & 613 & 224 & 0.19 & 0.20 \\
Nano-SAPO-34-42days & 561 & 223 & 0.18 & 0.20 \\
Nano-SAPO-34-107days & 536 & 223 & 0.15 & 0.20 \\
Standard-SAPO-34-5days & 460 & 63 & 0.19 & 0.11 \\
Standard-SAPO-34-29days & 463 & 62 & 0.19 & 0.11 \\
Standard SAPO-34-44days & 463 & 64 & 0.19 & 0.11 \\
\hline
\end{tabular}

Table 2. Distribution of silicon species by deconvolution of different ${ }^{29} \mathrm{Si}$ MAS NMR signal of samples of nano-SAPO-34 after exposure to moisture.

\begin{tabular}{lccccc}
\hline & 1 day & 7 days & 14 days & 21 days & 42 days \\
\hline Defects & 7.4 & 16.4 & 19.6 & 16.7 & 15.6 \\
Si4Al & 16.6 & 17.5 & 16.6 & 17.5 & 15.6 \\
Si3Al1Si & 23.6 & 18.3 & 17.8 & 16.6 & 17.7 \\
Si2Al2Si & 18.2 & 18.3 & 16.9 & 17.8 & 18.4 \\
Si1Al3Si & 13.9 & 12.8 & 13.3 & 13.5 & 13.8 \\
Si4Si & 20.3 & 16.5 & 15.6 & 17.6 & 18.7 \\
\hline
\end{tabular}

Table 3. Total acidity measured by $\mathrm{NH}_{3}$ Temperature Programmed Desorption after days of exposure to moisture

\begin{tabular}{cccc}
\hline Days & $\begin{array}{c}\text { Nano-SAPO-34 } \\
\left(\mathrm{mmol}_{\mathrm{NH} 3} \mathrm{~g}^{-1} \text { zeolite }\right)\end{array}$ & Days & $\begin{array}{c}\text { Standard-SAPO-34 } \\
\left(\mathrm{mmol}_{\mathrm{NH} 3} \mathrm{~g}^{-1} \text { zeolite }\right)\end{array}$ \\
\hline 1 & 1.03 & 1 & 1.01 \\
30 & 0.86 & 28 & 0.97 \\
43 & 0.72 & 40 & 0.95 \\
\hline
\end{tabular}


Table 4. Kinetic parameters, halflifetime $\left(\mathrm{t}_{0.5}\right)$, breakthrough time $\left(\mathrm{t}_{0.8}\right)$, and methanol conversion capacity of nano and standard-SAPO-34 samples obtained by fitting of Janssen's kinetic model.

\begin{tabular}{|c|c|c|c|c|c|c|}
\hline Sample & $\begin{array}{l}\text { Days of } \\
\text { exposure to } \\
\text { moisture }\end{array}$ & $\mathrm{k}(\mathrm{mol} / \mathrm{gh})$ & $\begin{array}{c}\mathrm{a} \\
(\mathrm{mmol} / \mathrm{g})\end{array}$ & $\begin{array}{c}\mathrm{t}_{0.5} \\
(\mathrm{~min})\end{array}$ & $\mathrm{t}_{0.8}$ (min) & $\begin{array}{c}\text { Methanol conversion } \\
\text { capacity } \\
\left(\mathrm{g}_{\text {metanol }} / \mathrm{g}_{\text {catalyst }}\right)\end{array}$ \\
\hline \multirow{6}{*}{$\begin{array}{l}\text { Nano- } \\
\text { SAPO-34 }\end{array}$} & 1 & 9.98 & 5.59 & 146 & 77 & 15.9 \\
\hline & 7 & 8.60 & 4.10 & 200 & 89 & 21.7 \\
\hline & 14 & 8.84 & 3.13 & 262 & 121 & 28.4 \\
\hline & 28 & 6.82 & 3.55 & 231 & 70 & 25.1 \\
\hline & 45 & 7.33 & 4.18 & 196 & 69 & 21.3 \\
\hline & 93 & 6.33 & 10.4 & 79 & 20 & 14.9 \\
\hline \multirow{3}{*}{$\begin{array}{l}\text { Standard- } \\
\text { SAPO-34 }\end{array}$} & 1 & 5.92 & 5.97 & 137 & 27 & 14.9 \\
\hline & 32 & 4.17 & 10.6 & 78 & $<0$ & 8.4 \\
\hline & 41 & 4.72 & 10.1 & 81 & $<0$ & 8.8 \\
\hline
\end{tabular}

Table 5. Initial and steady-state distribution of olefins in the conversion of Methanol to Olefins at $400^{\circ} \mathrm{C}$, WHSV $7 \mathrm{~h}^{-1}$ on Standard-SAPO-34 (1day) and Nano-SAPO-34 (14days). Thermodynamic equilibrium of $\mathrm{C} 2-\mathrm{C} 5$ olefins calculated at $\mathrm{P}=0.04 \mathrm{bar}$ of methanol and $\mathrm{T}=400^{\circ} \mathrm{C}$ by minimization of the total Gibbs energy of the system, method of the undetermined Lagrange's multipliers ${ }^{63}$. Free Gibbs standard formation energy of different olefins were taken from Alberty et al. ${ }^{64}$

\begin{tabular}{l|cc|cc|cc}
\hline & \multicolumn{2}{|c|}{$\begin{array}{c}\text { Thermodynamic } \\
\text { equilibrium }\end{array}$} & \multicolumn{2}{c|}{ Standard-SAPO-34 } & \multicolumn{2}{c}{ Nano-SAPO-34 } \\
\cline { 2 - 7 } & $\begin{array}{c}\text { Linear } \\
\text { olefins }\end{array}$ & $\begin{array}{c}\text { Linear+Branched } \\
\text { olefins }\end{array}$ & $\begin{array}{c}\text { Initial olefin } \\
\text { distribution }\end{array}$ & $\begin{array}{c}\text { Steady- } \\
\text { state }\end{array}$ & $\begin{array}{c}\text { Initial olefin } \\
\text { distribution }\end{array}$ & $\begin{array}{c}\text { Steady- } \\
\text { state }\end{array}$ \\
\hline C2 & 17.8 & 15 & 30 & 36.1 & 25 & 31 \\
C3 & 47.8 & 38.3 & 43.3 & 43.3 & 36.2 & 37.2 \\
C4 & 28.2 & 26.8 & 19.5 & 15.5 & 25.1 & 21.1 \\
C5+ & 6.2 & 19.9 & 7.2 & 5.2 & 13.7 & 10.8 \\
\hline
\end{tabular}




\section{Figure captions}

Fig.1. XRD patterns of calcined nano-SAPO-34 (A) after exposure to moisture for a) 1 day, b) 7 days, c) 14days, d) 21days, e) 42days; and standard-SAPO-34 (B) for a) 1 day, b) 21 days, c) 42 days.

Fig.2. SEM pictures of (A) nano-SAPO-34, (B) standard-SAPO-34, and (C) TEM of nano-SAPO-34.

Fig.3. $\mathrm{N}_{2}$ adsorption-desorption isotherms of nano and standard-SAPO-34.

Fig.4. ${ }^{27} \mathrm{Al}$ MAS NMR after exposure to moisture of (A) nano-SAPO-34 a) 1 day, b) 7 days, c) 14 days, d) 21 days e) 42days, (B) standard-SAPO-34 a) 21 day b) 32 days c) 40 days.

Fig.5. ${ }^{29}$ Si MAS NMR after exposure to moisture of (A) nano-SAPO-34 a) 1 day, b) 7 days, c) 14 days, d) 21 days e) 42days, (B) standard-SAPO-34 a) 21 day b) 32 days c) 40 days.

Fig.6. ${ }^{31}$ P MAS NMR after exposure to moisture of (A) nano-SAPO-34 a) 1 day, b) 7 days, c) 14 days, d) 21 days e) 42days, (B) standard-SAPO-34 a) 21 day b) 32 days c) 40 days.

Fig.7. FTIR in the OH range of nano-SAPO-34 after exposure to moisture.

Fig.8. FTIR in the OH stretching range of fresh nano-SAPO-34 after adsorption of $8.5 \mathrm{mb}$ of CO. Spectra subtracted from the parent sample free of CO.

Fig.9. FTIR in the CO stretching range after adsorption of $0.4 \mathrm{mb}$ of $\mathrm{CO}$ on nano-SAPO-34 samples exposed to moisture for 1, 7, 14 and 21 days. Spectra subtracted from the parent sample free of CO.

Fig.10 Conversion of Methanol at $400^{\circ} \mathrm{C}$ and WHSV: $7 \mathrm{~h}^{-1}$ on nano-SAPO-34 and standardSAPO-34 samples after exposure to moisture. Lines correspond to the fitting following the Jannssens's kinetic model.

Fig.11 Selectivities to C2, C3, C4 and C5+ hydrocarbons in the conversion of Methanol on nano-Sapo-34 and standard-SAPO-34 samples after 1 day of exposition to moisture.

Fig.12. C2/C3 ratio for nano and standard-SAPO-34 in the conversion of methanol at $400^{\circ} \mathrm{C}$ and WHSV $=7 \mathrm{~h}^{-1}$.

Fig.13. Proposed consecutive mechanism in the conversion of Methanol on SAPO-34 taking into account secondary equilibration of olefins.

Electronic Supplementary Information

Fig.S1. Nitrogen desorption isotherms of nano-SAPO-34 after a)7, b)28, c)42 and d)107 days of exposition to moisture.

Fig.S2. Nitrogen desorption isotherms of standard-SAPO-34 after a)5, b)29 and c)44 days of exposition to moisture.

Fig.S3. Yields to C2, C3, C4 and C5+ hydrocarbons in the conversion of Methanol on nano-Sapo-34 (21 days exposed to moisture) at different WHSV $\left(7,11,15 \mathrm{~h}^{-1}\right)$ at $400^{\circ} \mathrm{C}$. 
Fig.S4. Selectivities to C2, C3, C4 and C5+ hydrocarbons in the conversion of Methanol on nano-Sapo-34 after exposure to moisture for 1, 7, 14 and 21 days.

Fig.S5. Selectivities to C2, C3, C4 and C5+ hydrocarbons in the conversion of Methanol on standard-SAPO-34 after exposure to moisture for 1, 31 and 44 days. 

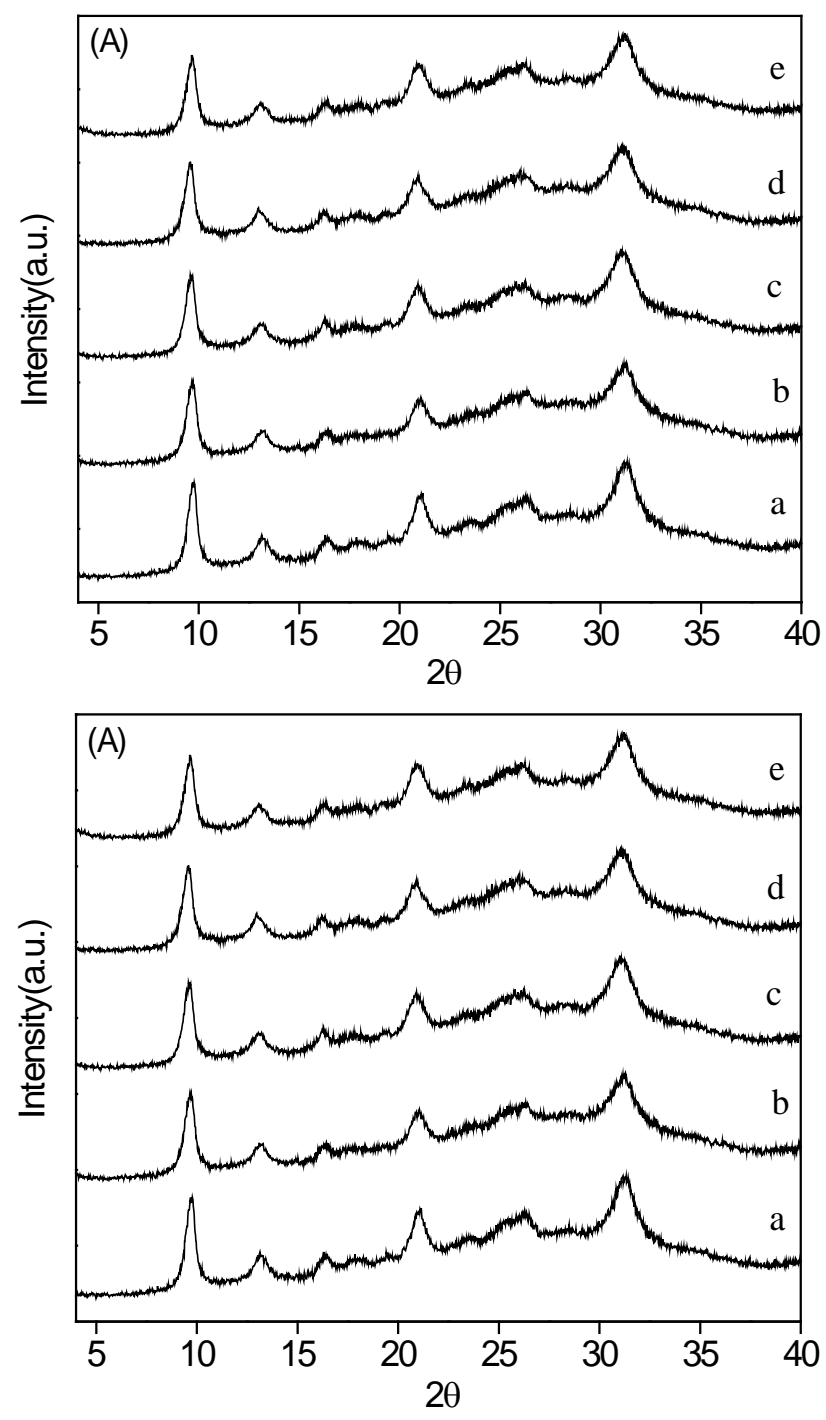

Figure 1 

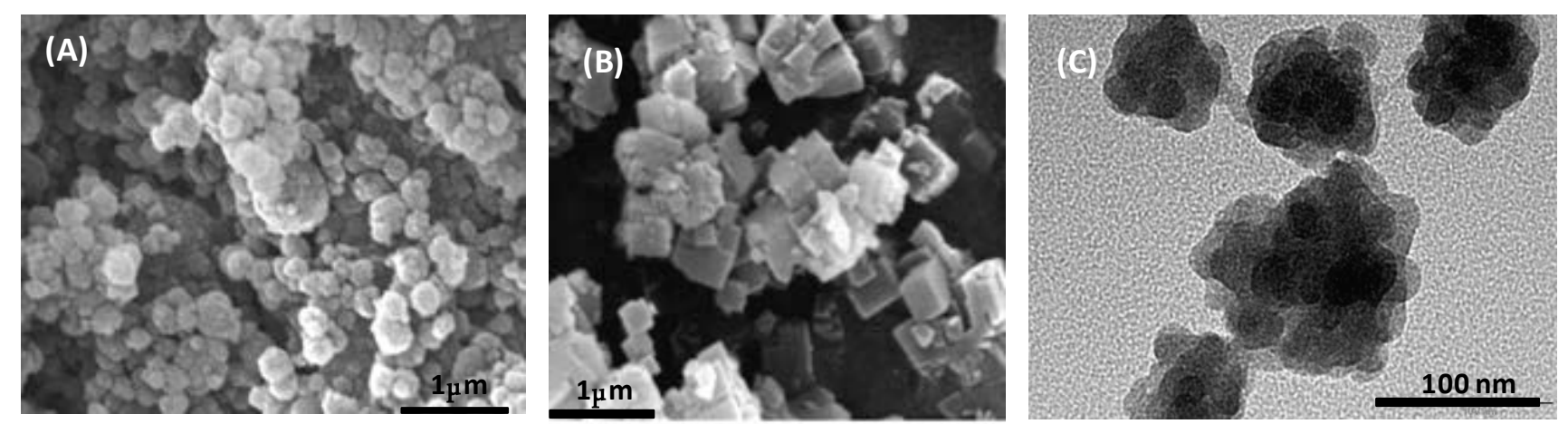

Figure 2 


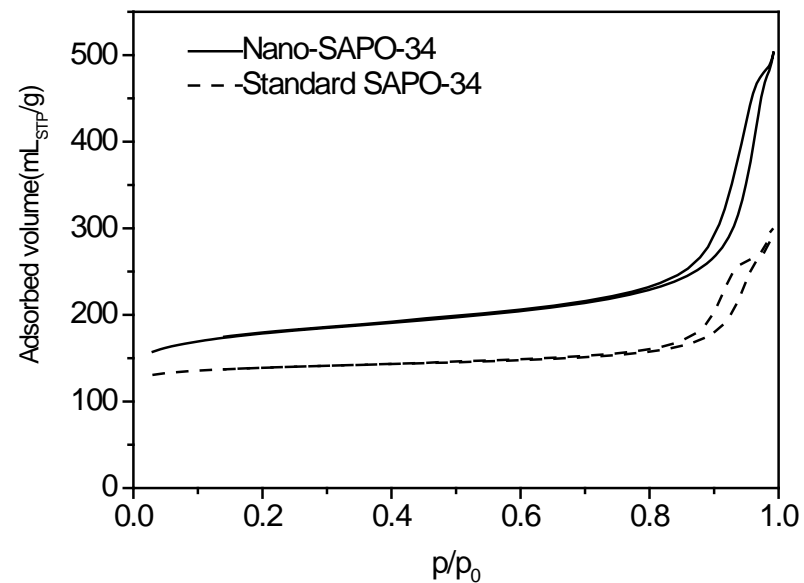

Figure 3 


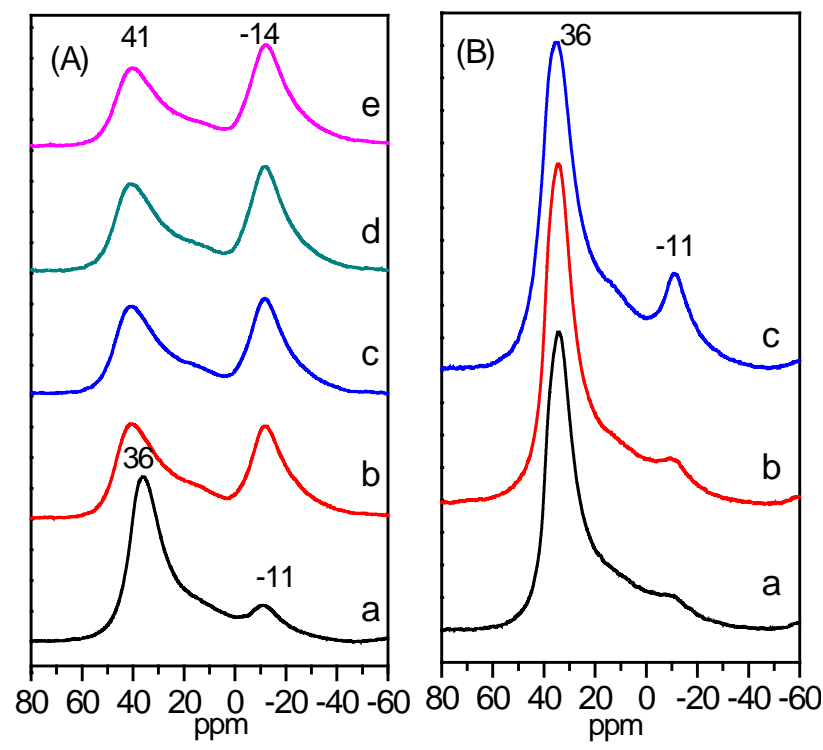

Figure 4 


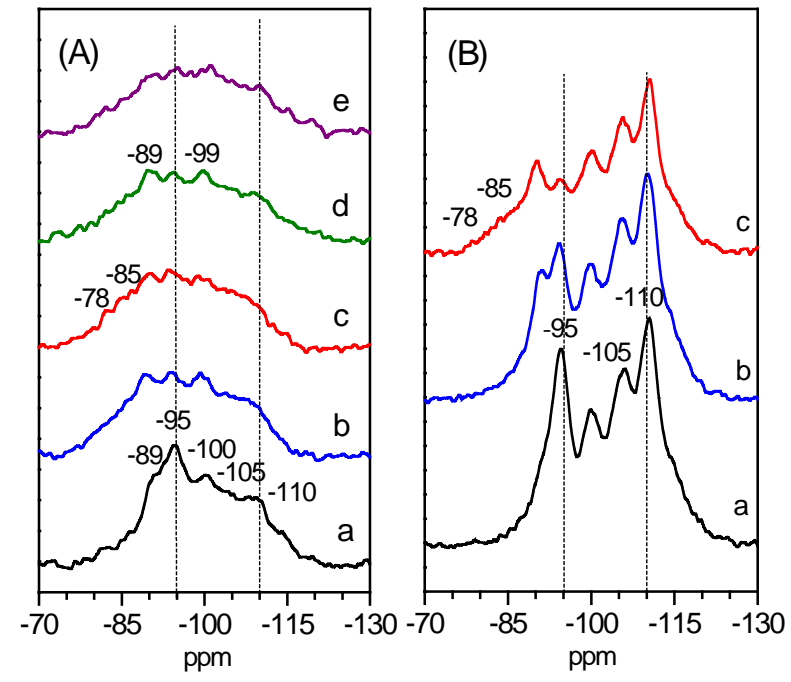

Figure 5 


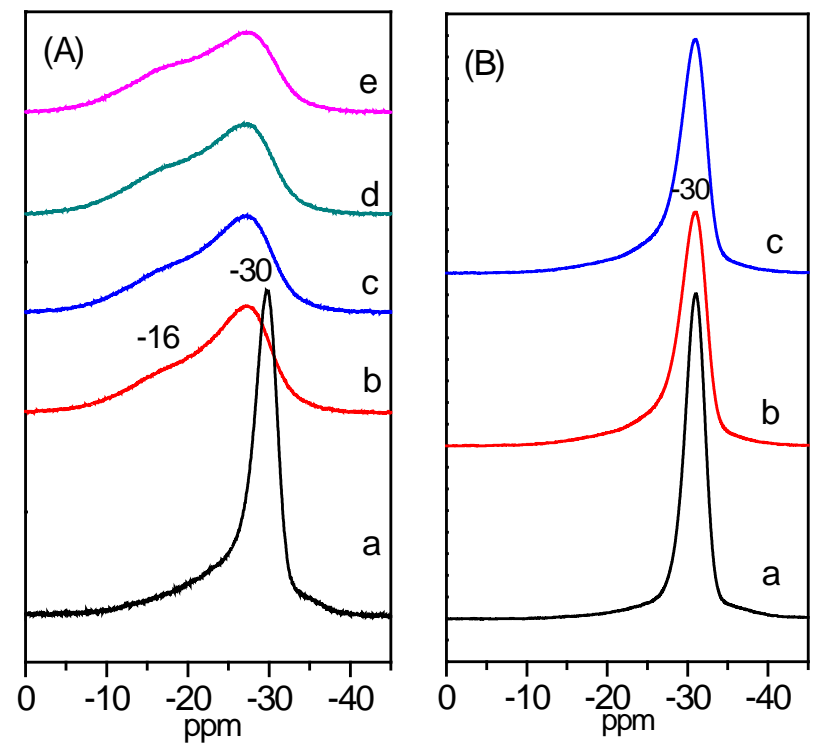

Figure 6 


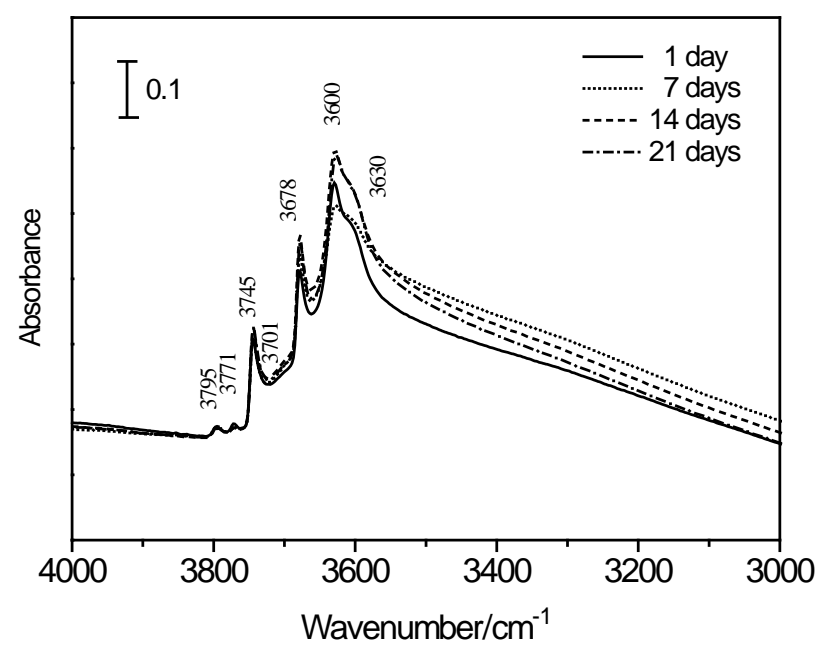

Figure 7 


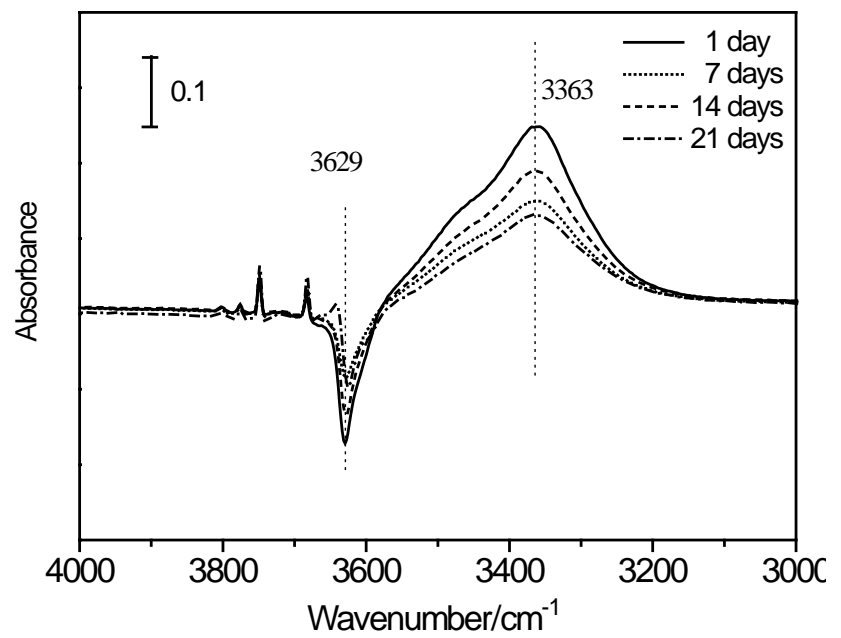

Figure 8 


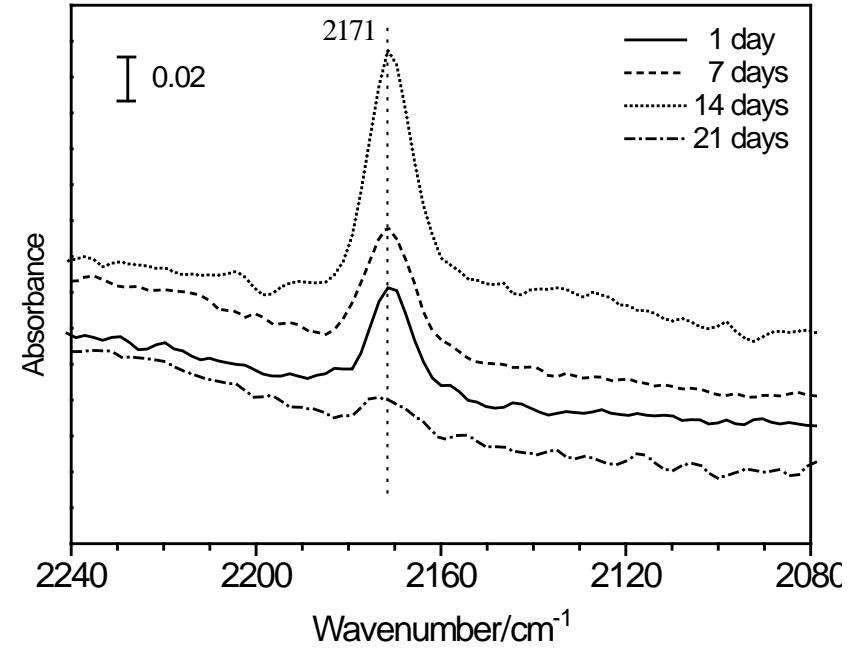

Figure 9 

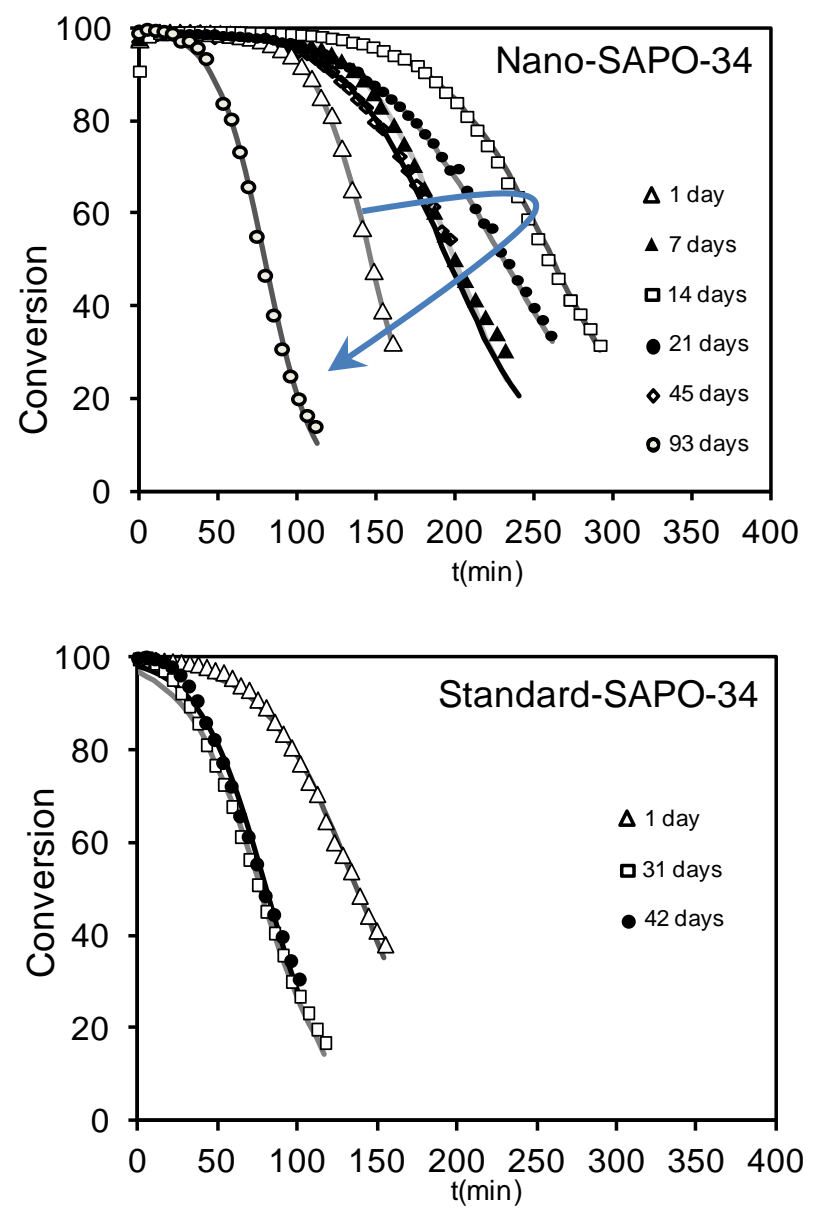

Figure 10 

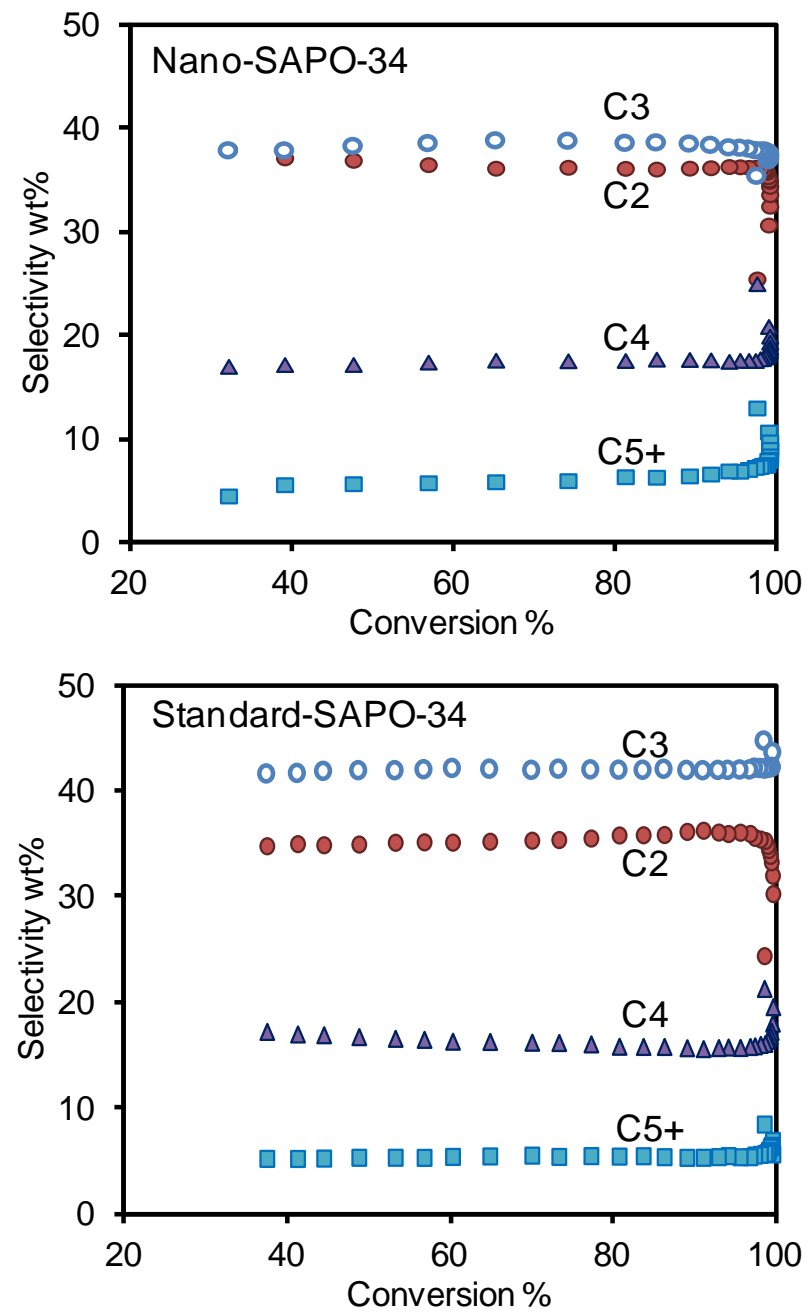

Figure 10 


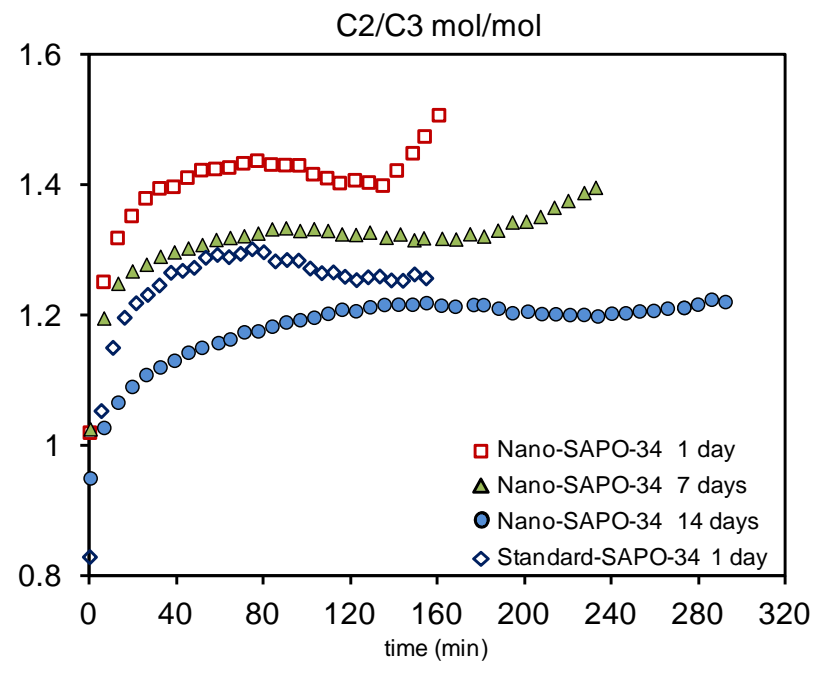

Figure 12 


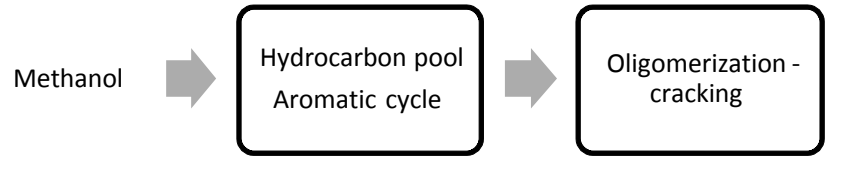

Figure 13 


\section{Electronic Supporting Information}

\section{Methanol to olefins: Activity, stability of nanosized SAPO-34 molecular sieve and control of selectivity by silicon distribution}

Zhibin Li ${ }^{1}$, Joaquin Martínez-Triguero ${ }^{1}$, Patricia Concepción ${ }^{1}$, Jihong $\mathrm{Yu}^{2}$, Avelino Corma ${ }^{\text {* }}$

${ }^{1}$ Instituto de Tecnología Química (UPV-CSIC), Universidad Politécnica de Valencia, Consejo Superior de Investigaciones Científicas, Av. de los Naranjos s/n, 46022 Valencia, Spain

${ }^{2}$ State Key Laboratory of Inorganic Synthesis and Preparative Chemistry, College of Chemistry, Jilin University, Changchun, 130021.China. 


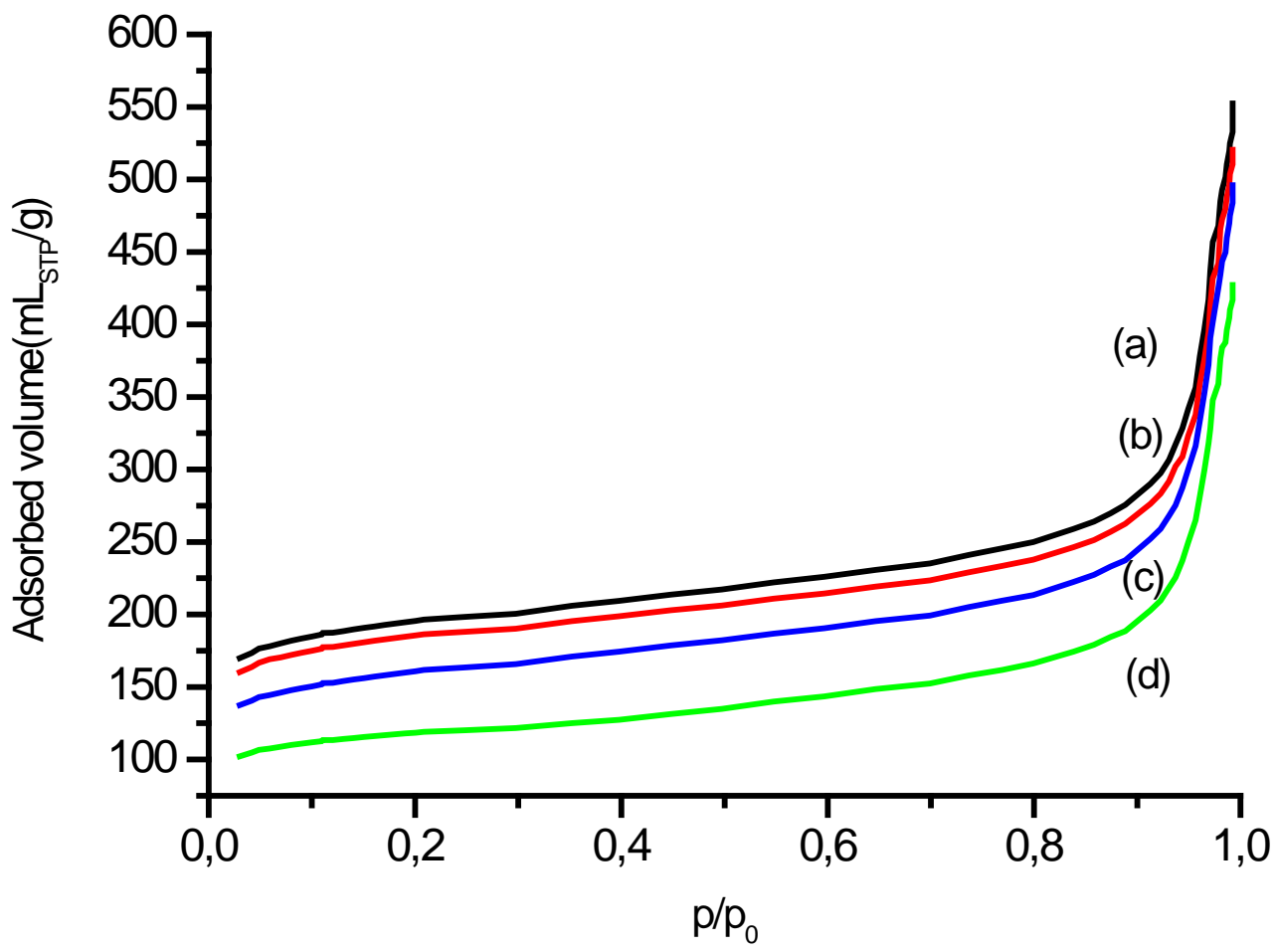

Fig.S1. Nitrogen desorption isotherms of nano-SAPO-34 after a)7, b)28, c)42 and d)107 days of exposition to moisture.

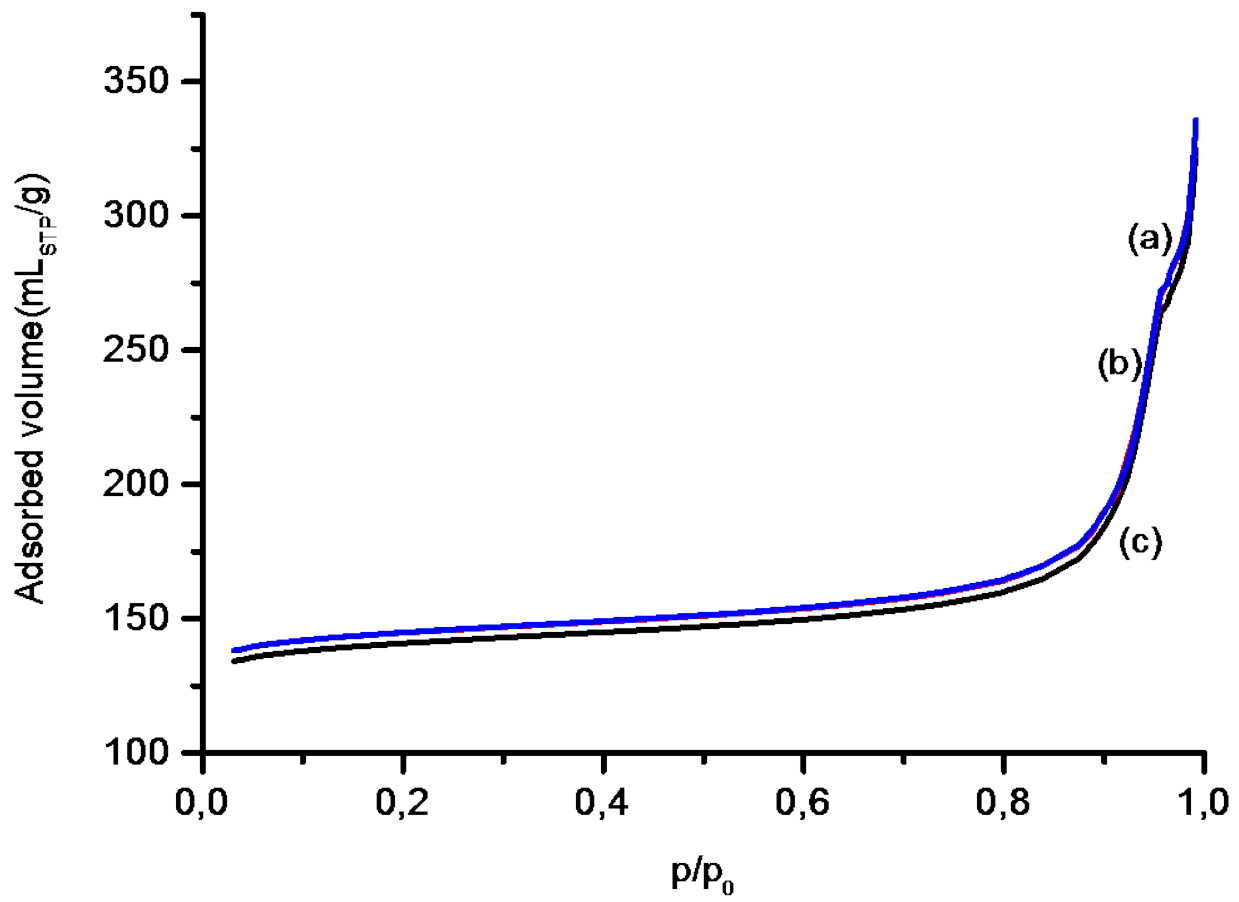

Fig.S2. Nitrogen desorption isotherms of standard-SAPO-34 after a)5, b)29 and c)44 days of exposition to moisture. 


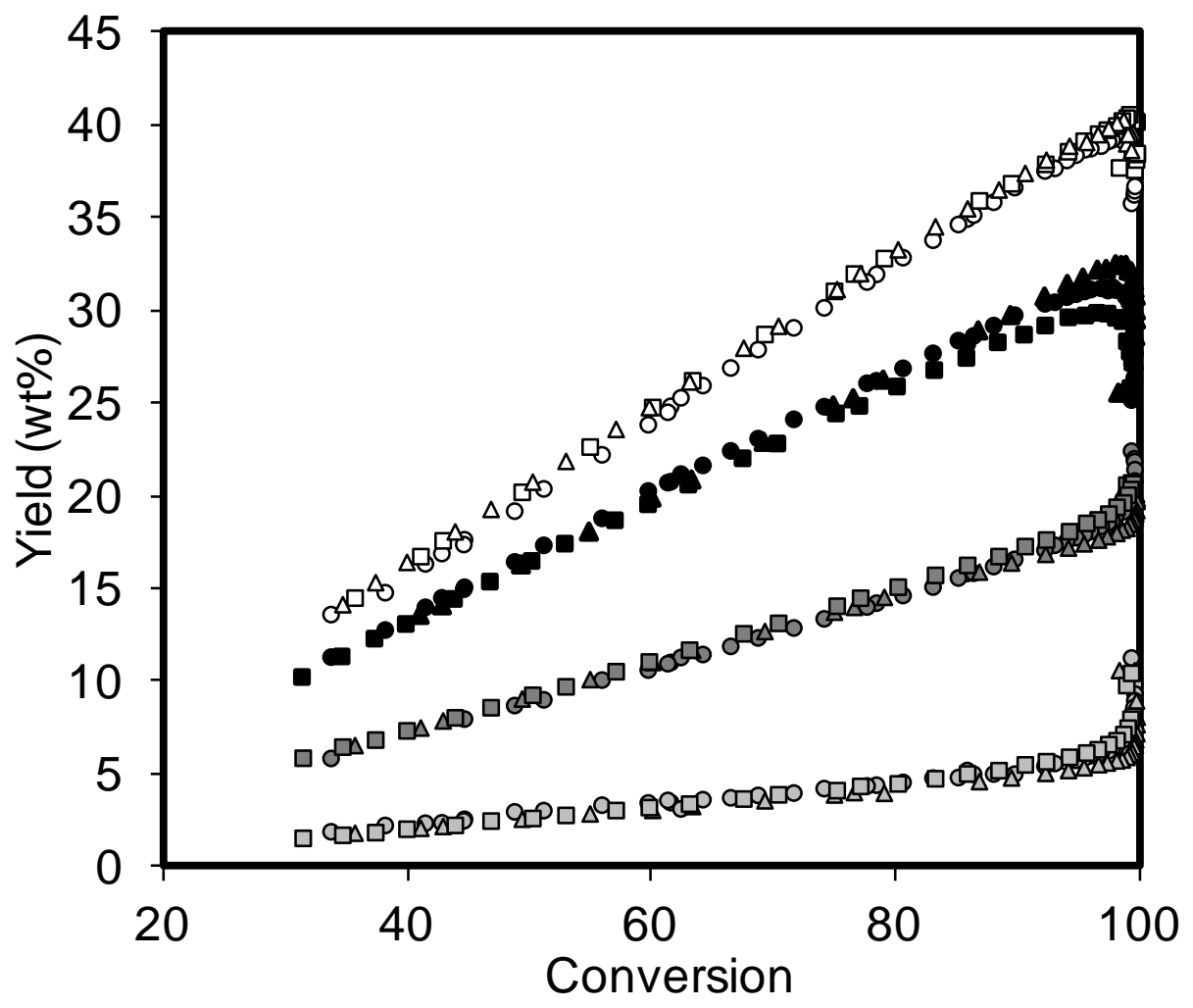

Fig.S3. Yields to C2, C3, C4 and C5+ hydrocarbons in the conversion of Methanol on nano-Sapo-34 (21 days exposed to moisture) at different WHSV (7, 11, $15 \mathrm{~h}^{-1}$ ) at $400^{\circ} \mathrm{C}$. 
$1 d$

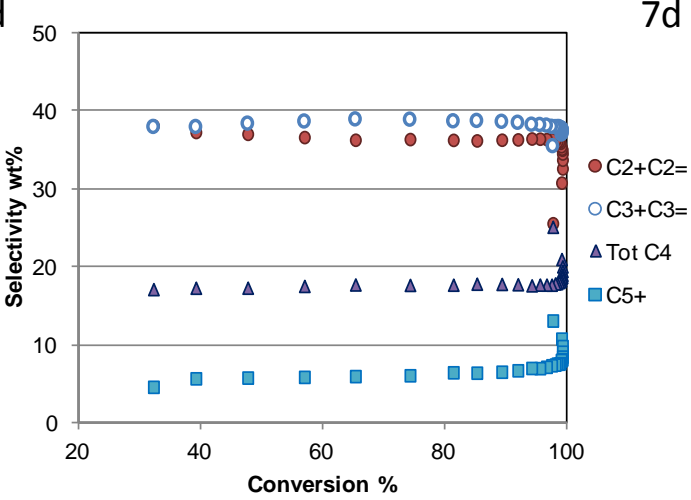

$14 d$

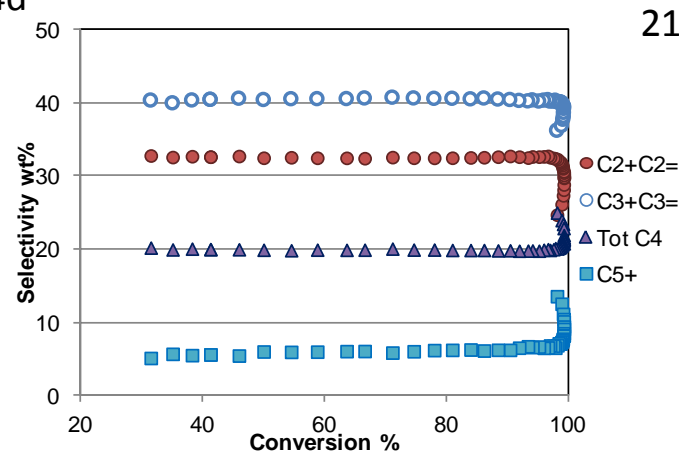

$7 d$

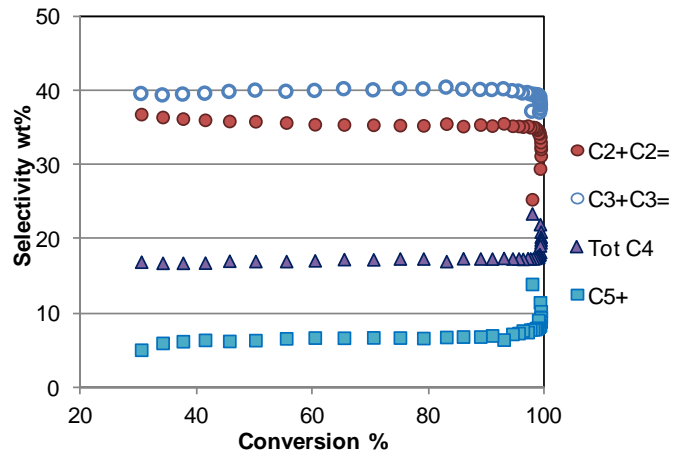

21d

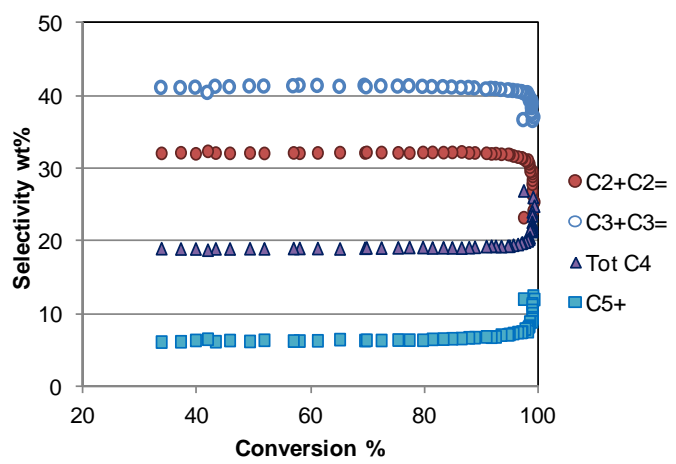

Fig.S4. Selectivities to C2, C3, C4 and C5+ hydrocarbons in the conversion of Methanol on nano-Sapo-34 after exposure to moisture for 1, 7, 14 and 21 days.

$1 d$

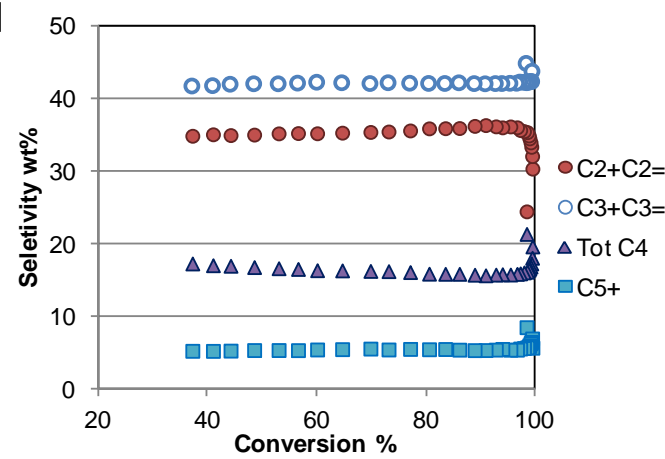

$41 d$

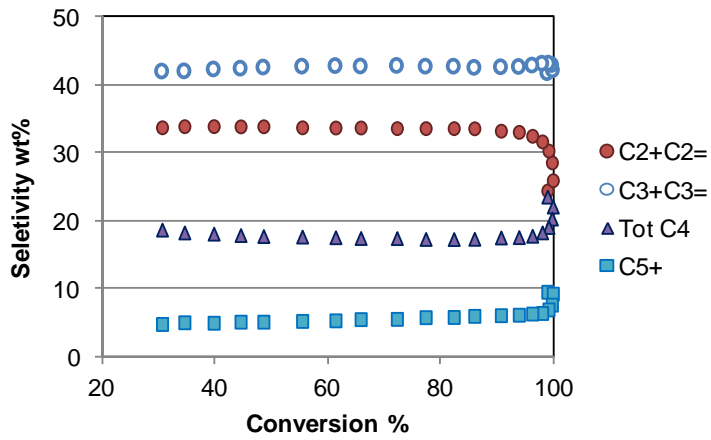

$32 d$

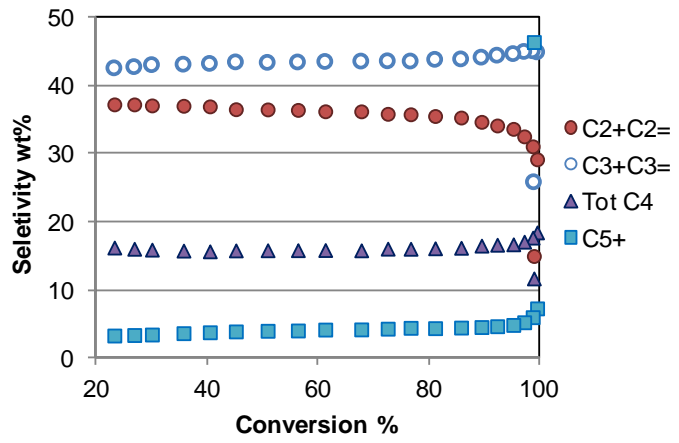

Fig.S5. Selectivities to C2, C3, C4 and C5+ hydrocarbons in the conversion of Methanol on standard-SAPO-34 after exposure to moisture for 1, 31 and 44 days. 